\title{
Soluble guanylate cyclase contribute genetic susceptibility to essential hypertension in the Han Chinese population
}

\author{
Yan Chen ${ }^{1,2}$, Lijun Zhu ${ }^{2}$, Zhengmei Fang ${ }^{2}$, Yuelong Jin ${ }^{2}$, Chong Shen ${ }^{3}$, Yingshui Yao ${ }^{2}$, Chengchao Zhou ${ }^{1,4}$ \\ ${ }^{1}$ Department of Social Medicine and Maternal \& Child Health, School of Public Health, Shandong University, Jinan 250012, China; ${ }^{2}$ Department \\ of Epidemiology and Biostatistics, School of Public Health, Wannan Medical College, Wuhu 241002, China; ${ }^{3}$ Department of Epidemiology, School \\ of Public Health, Nanjing Medical University, Nanjing 211166, China; ${ }^{4}$ NHC Key Laboratory of Health Economics and Policy Research, Shandong \\ University, Jinan 250012, China \\ Contributions: (I) Conception and design: Y Yao, C Zhou; (II) Administrative support: C Shen, Y Jin; (III) Provision of study materials or patients: : C \\ Shen; (IV) Collection and assembly of data: Y Chen, L Zhu, Z Fang; (V) Data analysis and interpretation: Y Chen,Y Yao, C Zhou; (VI) Manuscript \\ writing: All authors; (VII) Final approval of manuscript: All authors. \\ Correspondence to: Chong Shen. Department of Epidemiology, School of Public Health, Nanjing Medical University, No.101 Longmian Avenue, \\ Jiangning District, Nanjing 211166, China. Email: sc100@126.com; Yingshui Yao. Department of Epidemiology and Biostatistics, School of \\ Public Health, Wannan Medical College, NO.22 Wenchang West Road, Wuhu 241002, China. Email: yingshuiyao@163.com; Chengchao Zhou. \\ Department of Social Medicine and Maternal \& Child Health, School of Public Health, Shandong University, NO.44 Wenhua West Road, Jinan \\ 250012, China. Email: zhouchengchao@sdu.edu.cn.
}

\begin{abstract}
Background: Animal study found that soluble guanylate cyclase (sGC) plays an important role in development of hypertension (HT) by affecting the NO-sGC-CGMP signaling pathway. This study aims to evaluate the association of sGC with essential hypertension $(\mathrm{EH})$ in the Han Chinese population.

Methods: This case-control study included 2,012 hypertensive cases and 2,210 controls, and 6 tagging single nucleotide polymorphisms (SNPs) were selected (rs3806777, rs3806782, rs3796576 and rs7698460 in GUCY1A3, as well as rs2229202 and rs1459853 in GUCY1B3). Then the association of the six SNPs with $\mathrm{EH}$ was further evaluated in this study.

Results: The results indicated that the A/A genotype of rs1459853 in GUCY1B3 was associated with higher HT risk, and the odds ratio (OR) of its recessive model was 1.191 ( $\mathrm{P}=0.044)$. After adjusting for covariates, the association was still significant. Further stratification analyses showed that rs 1459853 in nondrinking subjects and rs7698460 in women were associated with EH. In the follow-up study, rs1459853 were related to increased HT risk in men and smoker subjects. In adolescents, rs2229202 that in GUCY1B3 had significant association with prehypertension (Pre-HT), HT, and prehypertension with hypertension (Pre-HT + HT). After adjusted for covariates, the association was remaining significant. And in girls, rs3806782 was significantly connected with HT and Pre-HT + HT.
\end{abstract}

Conclusions: Overall, our findings suggest that sGC may contribute to the genetic susceptibility to EH, and it was validated for the first time in adolescents.

Keywords: Soluble guanylate cyclase (sGC); essential hypertension (EH); polymorphism

Submitted Aug 10, 2019. Accepted for publication Oct 25, 2019.

doi: $10.21037 /$ atm.2019.11.49

View this article at: http://dx.doi.org/10.21037/atm.2019.11.49

\section{Introduction}

Nitric oxide (NO) is an important factor in the development of hypertension (HT). The endothelial damage and dysfunction induced by oxidative stress and inflammation mediated by $\mathrm{NO}$ were the fundamental reasons for the increase of peripheral arterial resistance and blood pressure (BP) $(1,2)$. Soluble guanylate cyclase (sGC), as the only receptor for $\mathrm{NO}$, is a key core metal enzyme in the NO 
signal transduction pathway (3). Abnormal NO-sGCCGMP signaling pathway could cause the dysfunction of endothelial cells, which was the key to the occurrence of HT (4).

Animal studies confirmed that each subunit of sGC plays an important role in the regulation of HT by affecting the NO-sGC-CGMP signaling pathway. The results of previous study indicated that $\mathrm{BP}$ was elevated in the absence of $s G C \alpha 1$ or $s G C \beta 1$ gene knockout mice, and downregulated expression of sGC was also found in HT models of rat (5-7). In addition, the genome-wide association study showed that the non-coding mutation in the GUCY1B3 region rs13139571 was associated with changes in BP (8). A study of Chinese population also confirmed that rs13143871 mutation of GUCY1A3 gene increase the risk of HT (9). Further study found that the mutation of Cys517Tyr in GUCY1A3 significantly weaken NO signal pathway, and lead to the occurrence of HT accordingly $(1,9,10)$.

The aim of this study was to confirm the relationship between all possible genetic polymorphisms of GUCY1A3 and genetic susceptibility to HT in different populations, and to analyze the interaction of gene-gene, geneenvironment-behavior factors, which may provide the basis for the pathogenesis of HT.

\section{Methods}

\section{Subjects}

\section{The case-control study of adult}

A total of 2,012 cases of patients with essential hypertension $(\mathrm{EH})$ and 2,210 cases of healthy control aged 35 to 75 years were recruited from a rural population in Yixing (Jiangsu province). The hypertensive cases were selected according to systolic blood pressure (SBP) $\geq 140 \mathrm{mmHg}$, and/or diastolic blood pressure (DBP) $\geq 90 \mathrm{mmHg}$, and/or current treatment with antihypertensive medications. The controls were normotensives that be matched for age- ( 5 years) and sex with SBP $<140 \mathrm{mmHg}$ and $\mathrm{DBP}<90 \mathrm{mmHg}$. Our work was approved by institutional review board of Nanjing medical university and informed consent was obtained from all subjects participating in the study.

\section{The follow-up study of adult}

In this study, excluded 94 elderly matched controls for the case-control study, 2,116 health controls were carried a median of 5.01 years follow-up survey from May 2014 to January 2016. Incidence information were collected from the hospital and chronic disease management system of the disease control center that in the chronic disease routine registration of local community health service center. Faceto-face or telephone surveys were performed to ascertain the subjects' disease status and the key information, and the physical and biochemical indicators of the follow-up subjects were reviewed. The follow-up time was calculated with the baseline participation date as the inclusion date, and the earliest occurrence date of hypertensive object for the finish time, while cases who died of other causes were followed up at the time of death. The time series for lost visitors was calculated at half of the end point of follow-up.

\section{Repeated validation in adolescents}

A total of 3,787 adolescents aged from 6 to 16 years old were investigated with an epidemiological cluster sampling in Yixing. BP of adolescents was defined by the percentile method according to "The Fourth Report on the Diagnosis, Evaluation, and Treatment of High Blood Pressure in Children and Adolescents" (11). Normal BP was defined as both SBP and DBP <90th percentile; prehypertension (Pre-HT) was defined as either SBP or DBP between $\geq 90$ th and $\leq 95$ th percentile; and HT was defined as either SBP or DBP $>95$ th percentile. In view of the effect of age, gender and height, the Z-scores of SBP and DBP in adolescents were calculated according to the method (www.cdc.gov/ growthcharts/) that provided by the US Centers for Disease Control and Prevention. In this study, 215 children with missing blood samples for genotyping and 21 children with missing BP, age, gender and/or height values were ruled out. Finally, 3,551 adolescents were investigated including 2,975 normotensive, 282 prehypertensive and 294 hypertensive.

\section{Baseline survey}

A standard questionnaire including demographic characteristics and medical history was carried to all subjects. Physical examinations including the BP, height, weight, waistline and Hip circumference, while lifestyle information such as smoking, drinking and physical activity were conducted. The body mass index (BMI) was calculated by weight $(\mathrm{kg}) /$ the square of height $\left(\mathrm{m}^{2}\right)$. Average $\mathrm{BP}$ values of three times were obtained with the participant in the sitting position after $5 \mathrm{~min}$ of rest. The participants were advised to avoid alcohol, smoking, coffee/tea, and exercise for at least $30 \mathrm{~min}$ before the BP measurement. Disease history and family history were mainly investigated for HT, diabetes, dyslipidemia, stroke and coronary heart disease. 
Smoking was defined as at least 20 cigarettes per week lasting 3 months every year. Drinking was defined as at least 2 times per week for more than half a year (12).

\section{Blood sampling and laboratory testing}

Five milliliter venous blood was collected from subjects under the condition of fasting in the morning by using EDTA anticoagulation blood-collecting tubes. Then the blood sampling was centrifuged within $24 \mathrm{~h}$ according to the standardized method, and the plasma was separated into two $1.5 \mathrm{~mL}$ centrifuge tubes. Total cholesterol (TC), triglycerides (TG), high-density lipoprotein cholesterol (HDL-C), low-density lipoprotein cholesterol (LDL-C) levels and glucose (GLU) were measured using a Biochemistry Auto-analyzer (Olympus C2734-Au640, Japan), and the remaining plasma was saved in $-20{ }^{\circ} \mathrm{C}$ freezer.

\section{Single nucleotide polymorphisms (SNPs) selection and genotyping}

We selected tagSNPs from the database of the Chinese Han population in Beijing (CHB), using the human reference genome (GRCh37, http://browser.1000genomes.org/ Multi/Search/Results). All tagSNPs were selected with the standard that minor allele frequency (MAF) $\geq 0.05$ and linkage disequilibrium $r^{2} \geq 0.8$. There were 68 sites (MAF >0.05) in the 2 and $1 \mathrm{~kb}$ regions of GUCY1A3 gene, and four tag-SNPs (rs3806777, rs3806782, rs3796576 and rs7698460) were selected according to the linkage imbalance method combined with the bioinformatics function prediction. The rs3806777 and rs3806782 were transcription factor binding sites (TFBS), and rs3796576 was miRNA binding sites. In addition, rs13139571, which was found to be associated with BP in the European population, was should be included in the analysis, yet rs7698460 which was provided to be TBFS according to bioinformatics analysis, is closely linked to rs13139571 both in the European population $\left(r^{2}=0.875\right)$ and the Chinese population $\left(r^{2}=0.968\right)$, so the $r s 13139571$ was replaced by rs7698460 in the analysis. In GUCY1B3, rs2229202 was in the shear modification region and rs1459853 was located in exon missense mutation (splice 5), both were included. As a result, 6 SNPs from GUCY1A3 and GUCY1B3 were analyzed in this study.

DNA was extracted by a standardized phenol-chloroform extraction, then the purity and concentration of DNA were determined by ultraviolet spectrophotometric method with nucleic acid protein analyzer (Thermo Nano Drop 2000, American Thermo corporations). SNPs were genotyped using TaqMan technology and ABI 7900HT Fast Real-Time PCR System (Applied BioSystems, Foster City, USA) (12). The primers and TaqMan-MGB probes were ordered from Applied BioSystems, and the Fast qPCR mix was purchased from Nanjing BioSteed BioTechologics (Nanjing, China). The identification of individual genotypes was performed by Sequence Detection System 2.1 software (ABI).

The study protocol was approved by the Research Ethics Committee of Nanjing Medical University, and informed consent was obtained from all samples of adults and the parents or guardians of all children.

\section{Statistical analysis}

The data were input into the database that established by Epidata3.0 (http://www.epidata.dk/), then imported into IBM SPSS 19.0 software for statically analysis. Measurement data were described by mean \pm standard deviation, and the difference between the case group and the control group was compared by two sample $t$-test (measurement data) or by Chi-square test (counting data). The allele frequency was calculated from the genotype frequency, and Fisher exact probability method was used to test Hardy-Weinberg $(\mathrm{H}-\mathrm{W})$ equilibrium. The frequency distribution of alleles and genotypes between the case group and the control group was compared by Chi-square test. The haplotype analysis with genetic variants was constructed using HAPSTAT 3.0 software (http://dlinWeb. Unc. Edu/ software/hapstat) and the covariates were adjusted as well. Multiple unconditional logistic regression was used to analyze the relationship between gene polymorphism and $\mathrm{HT}$ and to estimate odds ratio (OR) with corresponding $95 \%$ confidence interval (CI) after adjusted for gender, age, smoking, and drinking status. Cox's proportional hazard regression analysis were used to estimate the risk of GUCY1A3/GUCY1B3 and HT in the follow-up study with the hazard ratio (HR) and $95 \%$ CI. A two-tailed P value of 0.05 was defined as statistically significant.

\section{Results}

\section{Demographic characteristics}

The demographic and clinical characteristics of the total of 2,012 hypertensive cases and 2,210 normotensives adults 


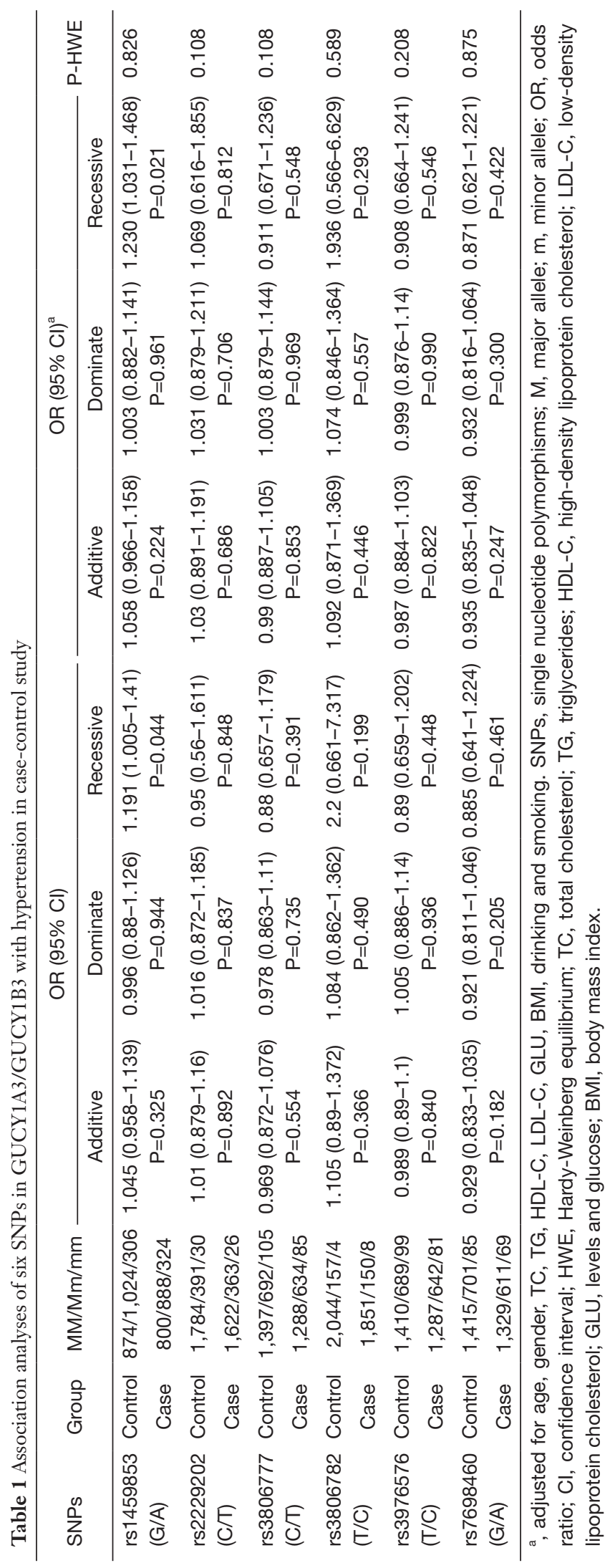

were shown in Table S1. According to the investigation, there was no statistically significant difference in the distribution of gender, smoking, drinking and HDL levels between the case and control group in this study $(\mathrm{P}>0.05)$. While the hypertensive cases had higher levels in DBP, SBP, TC, TG, LDL-C, GLU and BMI than the normotensive. In addition, the results showed that the average age of the case group was still 3. Forty-two years older than that of the control group $(\mathrm{P}<0.001)$. Although the control group had been matched with the case group according to age (5 years). Therefore, the age was corrected in the subsequent association analysis.

The 3,551 adolescents' demographic and clinical characteristics were listed in Table S2. The levels of z-SBP, z-DBP, TC, TG, LDL-C and BMI in Pre-HT group and HT group were higher than normotensive, and the differences were statistically significant $(\mathrm{P}<0.05)$, while the levels of HDL-C in the Pre-HT group and HT group were lower than normotensive $(\mathrm{P}=0.011)$.

\section{Single-locus association analyses}

The genotype distributions of the six tag-SNPs were in Hardy-Weinberg equilibrium (HWE) in the case-control study. Association study showed that, the A/A genotype of rs1459853 in GUCY1B3 was associated with higher HT risk [OR (95\% CI) was $1.191(1.005-1.41), \mathrm{P}=0.044]$. After adjusting for age, gender, TC, TG, LDL-C, HDL-C, GLU, BMI, smoking, and drinking, the statistics association between the A/A genotype of rs1459853 and HT was still significant [adjusted OR (95\% CI) was 1.230 (1.031-1.468), $\mathrm{P}=0.021]$ as showed in Table 1.

\section{Haplotype analyses}

Haploview 4.2 software was used to analyze and construct haplotype blocks, and the results showed that rs3806777 and rs3806782 on the GUCY1A3 gene were located in the Block of linkage imbalance section (Figure S1). CT with higher haplotype frequency was taken as a reference, there's no statistical significance was found between haplotype CC, TT and HT after adjusting for age, gender, smoking, drinking, GLU, TC, TG, HDL-C, LDL-C and BMI (Table S3).

\section{Stratification analyses}

Further stratification analyses showed that the statistics 
Table 2 Stratified analysis of the association that six SNPs with hypertension in case-control study

\begin{tabular}{llcccccc}
\hline SNPs & Group & Control & Case & OR (95\% Cl) & $P$ & OR $(95 \%$ Cl) \\
\hline rs7698460 additive & Men & $581 / 270 / 30$ & $539 / 254 / 35$ & $1.055(0.89-1.25)$ & 0.536 & $1.082(0.908-1.291)$ & 0.378 \\
& Women & $834 / 431 / 55$ & $790 / 357 / 34$ & $0.85(0.737-0.98)$ & 0.025 & $0.845(0.728-0.982)$ & 0.028 \\
& Non-drinking & $686 / 805 / 237$ & $635 / 692 / 262$ & $1.242(1.027-1.503)$ & 0.026 & $1.291(1.058-1.575)$ & 0.012 \\
rs1459853 recessive & Drinking & $188 / 219 / 69$ & $165 / 196 / 62$ & $1.013(0.699-1.468)$ & 0.945 & $1.029(0.698-1.517)$ & 0.885 \\
& & &
\end{tabular}

a, adjusted for age, gender, TC, TG, HDL-C, LDL-C, GLU, BMI, drinking and smoking. SNPs, single nucleotide polymorphisms; OR, odds ratio; $\mathrm{Cl}$, confidence interval; TC, total cholesterol; TG, triglycerides; HDL-C, high-density lipoprotein cholesterol; LDL-C, low-density lipoprotein cholesterol; GLU, levels and glucose; BMI, body mass index.

association of rs1459853 with HT was significant in nondrinking subjects [OR (95\% CI) was $1.242(1.027-1.503)]$ for the recessive model (AA vs. GA + GG). The variant of rs7698460 in GUCY1B3 was associated with lower HT risk in women, the OR (95\% CI) was $0.85(0.737-0.98)$ for the additive model (GG vs. GA vs. AA). After adjusting for age, gender, TC, TG, LDL-C, HDL-C, glucose, BMI, smoking, and drinking, the association remain significant (Tables 2,S4).

\section{Association analyses of incident HT in the follow-up study}

In this study, 613 instances of HT were followed up, with an incidence density of 6,570 per $10^{5}$ person years.

The results of Cox's proportional hazard regression analysis showed that no association was found between the six SNPs and the incidence of HT (Table S5). However, in men and smoker subjects, carriers of T/T genotype of rs2229202 in GUCY1B3 were associated with increasing the risk of HT, the HR (95\% CI) of additive models were 1.426 (1.097-1.854) and 1.504 (1.077-2.101), respectively. After adjusting for age, gender, TC, TG, HDL-C, LDL-C, BMI, drinking, smoking, and T2DM, the statistics association of the T/T genotype of rs2229202 with HT was still significant, similar results existed in the dominate model and the recessive model (Table 3). The detailed results data could be found in Table S6.

\section{Replication in adolescents}

In this study, the association of GUCY1A3/GUCY1B3 polymorphisms with HT was replicated in adolescents. The results showed that, the T/T genotype of rs 2229202 that in GUCY1B3 had significant association with Pre-HT, HT and Pre-HT + HT, the ORs (95\% CIs) of the additive model were 1.213 (1.007-1.462), 1.232 (1.027-1.478) and 1.223 (1.067-1.402), and the ORs (95\% CIs) of the dominate model were 1.330 (1.023-1.729), 1.461 (1.133$1.884)$ and $1.396(1.152-1.690)$ respectively (Table S7). After adjusted for covariates (including age, gender, BMI, TC, TG, HDL-C and LDL-C), the association between rs2229202 and HT as well as Pre-HT + HT was remind significant, the ORs (95\% CIs) of the dominate model were changed to be 1.391 (1.068-1.81), 1.331 (1.091-1.623), while the $\mathrm{P}$ values were transformed into 0.014 and 0.005 (Tables S8,S9).

Further stratification analyses by gender showed that, the genetic mutations of rs2229202 were significantly associated with HT and Pre-HT + HT in boys, the ORs (95\% CIs) of dominant model were 1.701 (1.197-2.417) and 1.56 (1.192-2.041), and the $\mathrm{P}$ values were 0.003 and 0.001 respectively, which were changed to 0.015 and 0.009 after adjusted for the covariates (including age, gender, BMI, TC, TG, HDL-C and LDL-C). Additionally, rs3806782 was significantly associated with HT and Pre-HT + HT in girls, ORs (95\% CIs) of dominant model were 1.933 (1.133-3.298) and 1.62 (1.059-2.478), and the $P$ values were 0.016 and 0.026 while changed to be 0.015 and 0.022 after adjust for covariates (Table 4). The detailed results were listed in Tables S10,S11.

\section{Discussion}

This study describes the sGC gene (GUCY1A3 and GUCY1B3) of BP and HT in Chinese to date involving a total of 4,222 individuals. We observed carriers of the A/ A genotypes and A allele of rs1459853 (GUCY1B3) was increased risk of HT in the case-control study, and the association was more significant in non-drinking groups. Besides, stratified analysis showed that rs7698460 of GUCY1A3 had associations with HT in female. In followup study, rs2229202 of GUCY1B3 had associations with the increased risk of HT in $\geq 55$ years group, man, smoking 
and drinking population. And the association of rs2229202 with pre-HT/HT was further replicated in adolescents' males. These results indicated that the effects of variants in the GUCY1A3 and GUCY1B3 gene might contribute to the processes of HT.

sGC can be regarded as an important media, which not only is the unique receptor of carbon monoxide in vascular smooth muscle cells but also is a potential new drug target in the pathophysiology of HT (13). Diminished expression and function of sGC contributes to the pathogenesis of several cardiovascular diseases such as coronary artery disease (CAD), atherosclerosis and HT (14). Despite the prominent role of NO-sGC-cGMP signaling pathway in regulating vascular functions, sGC gene further arouse interest in the study of cardiovascular diseases.

The impact of genetic variation in the GUCY1A3 gene on human atherosclerosis has been highlighted by previous studies that showed a unique digenic loss-of-function mutation affecting GUCY1A3 to segregate with CAD and myocardial infarction (15). Besides, the locus rs13139571 is located within an intron of GUCY1A3 and its minor allele is associated with higher BP and odds of HT in a genome wide association study (8). In this study, we observed a negative association of $\mathrm{rs} 7698460 \mathrm{G}>\mathrm{A}$ variant of GUCY1A3 with HT in female. The lead SNP rs7698460, which is in moderate linkage disequilibrium with the BP related SNP rs13139571 $\left(\mathrm{r}^{2}=0.968\right)$ in Chinese population. Moreover, bioinformatics analysis showed that the variation of rs7698460 may affect the TFBS for cutl1, which is a target of TGF- $\beta$ signaling that modulate cell proliferation and differentiation and morphogenesis, contributing to vascular repair, remodeling (16).

GUCY1B3 has been shown to interact with endothelial nitric oxide synthase (NOS) which implicated in the pathology of several vascular diseases (17). Our previous studies indicated that NOS3 polymorphisms contribute to the genetic susceptibility of HT (13). Moreover, NO caused a dose-dependent increase in GUCY1B3 mRNA expression (18). The findings of present study revealed that the GUCY1B3 rs1459853 gene polymorphism might serve as predisposing factor in HT. It is plausible that rs1459853 $\mathrm{G}>\mathrm{A}$ is a splice variant that changes the 2-base region at the 5 ' end of an intron.

The result suggested that the GUCY1B3 rs2229202 $\mathrm{C}>\mathrm{T}$ polymorphism was associated with a higher risk of HT in $\geq 55$ years group, man, smoking and drinking population. Epidemiological studies have demonstrated a positive relationship between heavy alcohol use and 
Table 4 Stratification analyses by gender for association of GUCY1A3/GUCY1B3 with hypertension in adolescents

\begin{tabular}{|c|c|c|c|c|c|c|c|c|}
\hline SNPs & Group & $\mathrm{MM} / \mathrm{Mm} / \mathrm{mm}$ & \multicolumn{6}{|c|}{ OR (95\% Cl) } \\
\hline \multirow{3}{*}{$\begin{array}{l}\text { rs2229202 } \\
\text { (Boys) }\end{array}$} & Normal & $1,118 / 286 / 114$ & 1 & & 1 & & 1 & \\
\hline & Pre-HT & $89 / 31 / 14$ & $1.283(0.984-1.672)$ & 0.065 & 1.413 (0.97-2.059) & 0.072 & $1.437(0.8-2.58)$ & 0.225 \\
\hline & HT & $92 / 50 / 6$ & $1.223(0.945-1.582)$ & 0.126 & $1.701(1.197-2.417)$ & 0.003 & $0.52(0.225-1.204)$ & 0.127 \\
\hline \multirow{4}{*}{$\begin{array}{l}\text { rs3806782 } \\
\text { (Girls) }\end{array}$} & Normal & $1,347 / 86 / 12$ & 1 & & 1 & & 1 & \\
\hline & Pre-HT & $135 / 12 / 1$ & $1.216(0.718-2.058)$ & 0.467 & $1.324(0.723-2.424)$ & 0.364 & - & - \\
\hline & HT & $128 / 17 / 1$ & $1.614(1.019-2.556)$ & 0.041 & 1.933 (1.133-3.298) & 0.016 & - & - \\
\hline & Pre-HT + HT & $263 / 29 / 2$ & $1.416(0.98-2.045)$ & 0.064 & $1.62(1.059-2.478)$ & 0.026 & - & - \\
\hline
\end{tabular}

SNPs, single nucleotide polymorphisms; M, major allele; m, minor allele; OR, odds ratio; $\mathrm{Cl}$, confidence interval; HT, hypertension.

HT (19). Furthermore, smoking as an independent risk factor for HT (20). These stratification factors may play important modulating roles in the genetic effects of GUCY1B3 on HT susceptibility. The rs2229202 SNP, showing the features above in this study, is an intron mutation located at chromosome 4:155800046 (GRCh38. p7 assembly of the human genome). Introns are involved in regulation of alternative splicing and gene expression (21); therefore, the rs2229202 $\mathrm{C}>\mathrm{T}$ polymorphism may affect the $G U C Y 1 B 3$ gene splicing, and inhibit affinity for splicing factors and alter alternative splicing, leading to altered mRNA sequence and protein translation (22). So far, however, there is a lack of studies on rs2229202, and studies about an impact of rs2229202 on GUCY1B3 gene splicing do not exist.

GUCY1A3 and GUCY1B3 interact functionally with each other to form a sGC heterodimer involved in GDP/ GTP balance and NO-mediated signal transduction (6). HT reduces sGC expression in the mouse aorta via the Notch signaling pathway, which provides a constitutive drive on expression of the GUCY1A3/GUCY1B3, and this control mechanism is disturbed in HT (23).

The present study has several limitations. This observational study lacks the measurement of the serum sGC concentration and mechanistic research, and whether the mutation of GUCY1A3 and GUCY1B3 gene have impact on SGC concentration, and therefore increase the risk of HT. Another limitation is that our study only approached the association between GUCY1A3 and GUCY1B3 polymorphism and the risk of HT in the Chinese casecontrol and cohort study; thus, the exact mechanism on development of GUCY1A3 and GUCY1B3 through the SNP is still unknown. Therefore, attempts to verify the underlying mechanism is needed in the future.

\section{Conclusions}

In summary, our findings suggested that GUCY1A3 and GUCY1B3 genetic polymorphisms had significant association with $\mathrm{EH}$ in the Han Chinese population, and it was the first to be repeated validation in adolescents. Transcriptional control mechanisms for GUCY1A3 and GUCY1B3 represent a medically prioritized area of investigation that may uncover novel targets for therapy of HT.

\section{Acknowledgments}

Funding: This research was supported by the National Natural Science Foundation of China (N0.81874280 and No. 81673266); Anhui Provincial Natural Science Foundation (No. 1808085QH283 and No. 1808085MH297); The key Project University of Youth Talents fund of Anhui Province (No. 2013SQRL056ZD).

\section{Footnote}

Conflicts of Interest: The authors have no conflicts of interest to declare.

Ethical Statement: The authors are accountable for all aspects of the work in ensuring that questions related to the accuracy or integrity of any part of the work are appropriately 
investigated and resolved. The study protocol was approved by the Research Ethics Committee of Nanjing Medical University, and informed consent was obtained from all samples of adults and the parents or guardians of all children.

\section{References}

1. Al-Qattan KK, Thomson M, Al-Mutawa'a S, et al. Nitric oxide mediates the blood-pressure lowering effect of garlic in the rat two-kidney, one-clip model of hypertension. J Nutr 2006;136:774S-6S.

2. Pradhan $\mathrm{AD}$, Manson JE, Rifai N, et al. C-reactive protein, interleukin 6 , and risk of developing type 2 diabetes mellitus. JAMA 2001;286:327-34.

3. Pan J, Zhong FF, Wang HY, et al. Structural basis and molecular mechanism of soluble guanylatecyclase in NOsignaling transduction. Sci Sin Chim 2014;44:572-85.

4. HU L, YI R, LI Q. Advances in soluble guanylate cyclase stimulator. Journal of China Pharmaceutical University 2016;47:531-6.

5. Buys ES, Sips P, Vermeersch P, et al. Gender-specific hypertension and responsiveness to nitric oxide in sGCalpha1 knockout mice. Cardiovasc Res 2008;79:179-86.

6. Friebe A, Mergia E, Dangel O, et al. Fatal gastrointestinal obstruction and hypertension in mice lacking nitric oxidesensitive guanylyl cyclase. Proc Natl Acad Sci U S A 2007;104:7699-704.

7. López-Farré A, Rodriguez-Feo JA, García-Colis E, et al. Reduction of the soluble cyclic GMP vasorelaxing system in the vascular wall of stroke-prone spontaneously hypertensive rats: effect of the alpha1 -receptor blocker doxazosin. J Hypertens 2002;20:463-70.

8. International Consortium for Blood Pressure GenomeWide Association Studies, Ehret GB, Munroe PB, et al. Genetic variants in novel pathways influence blood pressure and cardiovascular disease risk. Nature 2011;478:103-9.

9. Lu X, Wang L, Lin X, et al. Genome-wide association study in Chinese identifies novel loci for blood pressure and hypertension. Hum Mol Genet 2015;24:865-74.

10. Wallace S, Guo DC, Regalado E, et al. Disrupted nitric oxide signaling due to GUCY1A3 mutations increases risk for moyamoya disease, achalasia and hypertension. Clin Genet 2016;90:351-60.

11. Falkner B, Daniels SR. Summary of the Fourth Report on the Diagnosis, Evaluation, and Treatment of High Blood Pressure in Children and Adolescents. Hypertension 2004;44:387-8.
12. Yao Y, Zhu L, Fang Z, et al. Insulin-Like Growth Factor-1 and Receptor Contribute Genetic Susceptibility to Hypertension in a Han Chinese Population. Am J Hypertens 2018;31:422-30.

13. Wang L, Shen C, Yang S, et al. Association study of NOS3 gene polymorphisms and hypertension in the Han Chinese population. Nitric Oxide 2015;51:1-6.

14. Belik J. Riociguat, an oral soluble guanylate cyclase stimulator for the treatment of pulmonary hypertension. Curr Opin Investig Drugs 2009;10:971-9.

15. Erdmann J, Stark K, Esslinger UB, et al. Dysfunctional nitric oxide signalling increases risk of myocardial infarction. Nature 2013;504:432-6.

16. Michl P, Ramjaun AR, Pardo OE, et al. CUTL1 is a target of TGF(beta) signaling that enhances cancer cell motility and invasiveness. Cancer Cell 2005;7:521-32.

17. Venema RC, Venema VJ, Ju H, et al. Novel complexes of guanylate cyclase with heat shock protein 90 and nitric oxide synthase. Am J Physiol Heart Circ Physiol 2003;285:H669-78.

18. Beckman JD, Grazul-Bilska AT, Johnson ML, et al. Isolation and characterization of ovine luteal pericytes and effects of nitric oxide on pericyte expression of angiogenic factors. Endocrine 2006;29:467-76.

19. Stranges S, Wu T, Dorn JM, et al. Relationship of alcohol drinking pattern to risk of hypertension: a populationbased study. Hypertension 2004;44:813-9.

20. Kim M, Kim M, Yoo HJ, et al. Associations between hypertension and the peroxisome proliferatoractivated receptor-delta (PPARD) gene rs7770619 C>T polymorphism in a Korean population. Hum Genomics 2018;12:28.

21. Jo BS, Choi SS. Introns: The Functional Benefits of Introns in Genomes. Genomics Inform 2015;13:112-8.

22. Fairbrother WG, Yeo GW, Yeh R, et al. RESCUE-ESE identifies candidate exonic splicing enhancers in vertebrate exons. Nucleic Acids Res 2004;32:W187-90.

23. Rippe C, Zhu B, Krawczyk KK, et al. Hypertension reduces soluble guanylyl cyclase expression in the mouse aorta via the Notch signaling pathway. Sci Rep 2017;7:1334.

Cite this article as: Chen Y, Zhu L, Fang Z, Jin Y, Shen C, Yao Y, Zhou C. Soluble guanylate cyclase contribute genetic susceptibility to essential hypertension in the Han Chinese population. Ann Transl Med 2019;7(22):620. doi: 10.21037/ atm.2019.11.49 


\section{Supplementary}

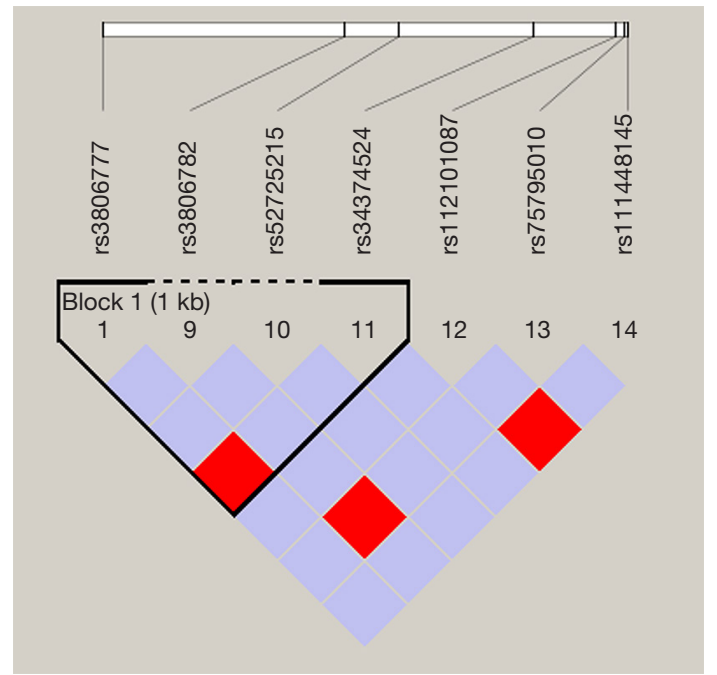

Figure S1 The haplotype of GUCY1A3.

Table S1 Comparison of clinical characteristics between HT cases and controls $[(\bar{x} \pm \mathrm{s}) /(\mathrm{n})]$

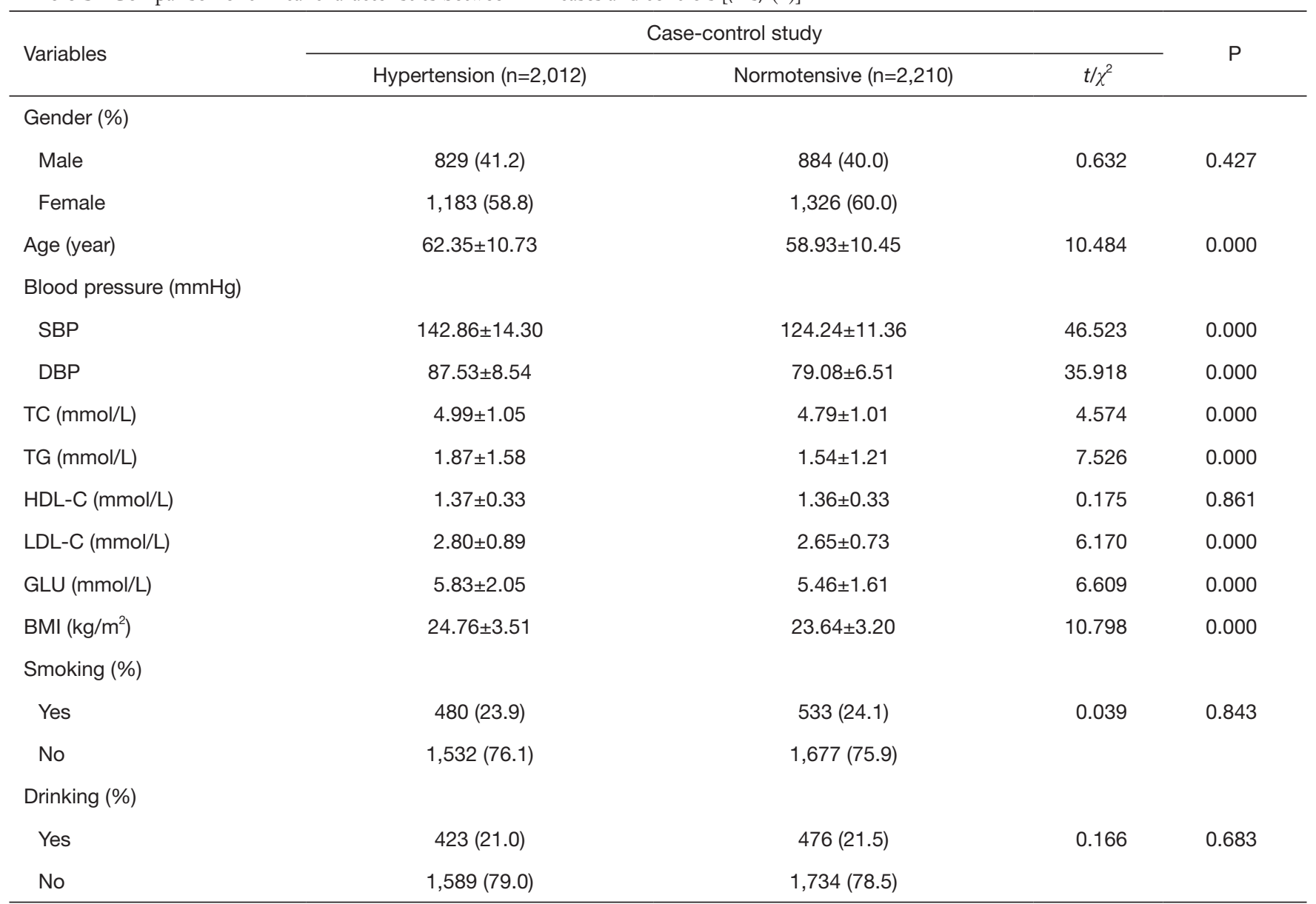

HT, hypertension; TC, total cholesterol; TG, triglycerides; HDL-C, high-density lipoprotein cholesterol; LDL-C, low-density lipoprotein cholesterol; GLU, levels and glucose; BMI, body mass index. 
Table S2 Comparison of clinical characteristics of the adolescents $[\bar{x} \pm \mathrm{S} /(\mathrm{n})]$

\begin{tabular}{|c|c|c|c|c|c|}
\hline Variables & Normotensive $(n=2,975)$ & Pre-HT $(n=282)$ & HT $(n=294)$ & $\mathrm{F} / \chi^{2}$ & $\mathrm{P}$ \\
\hline Boys & 1,526 & 134 & 148 & 1.512 & 0.469 \\
\hline Girls & 1,449 & 148 & 146 & & \\
\hline Age (year) & $11.02 \pm 2.92$ & $10.48 \pm 2.92$ & $10.64 \pm 2.94$ & 6.254 & 0.002 \\
\hline z SBP & $0.74 \pm 0.79$ & $2.02 \pm 0.58$ & $2.57 \pm 0.77$ & 1015.229 & $<0.001$ \\
\hline Z DBP & $0.15 \pm 0.51$ & $0.97 \pm 0.44$ & $1.35 \pm 0.57$ & 969.395 & $<0.001$ \\
\hline TC (mmol/L) & $3.91 \pm 0.68$ & $4.02 \pm 0.66$ & $4.02 \pm 0.71$ & 6.632 & 0.001 \\
\hline $\mathrm{TG}(\mathrm{mmol} / \mathrm{L})$ & $1.24 \pm 0.69$ & $1.35 \pm 0.91$ & $1.45 \pm 0.88$ & 12.824 & $<0.001$ \\
\hline BMI $\left(\mathrm{kg} / \mathrm{m}^{2}\right)$ & $18.13 \pm 3.60$ & $19.00 \pm 3.91$ & $20.08 \pm 4.64$ & 41.051 & $<0.001$ \\
\hline
\end{tabular}

TC, total cholesterol; TG, triglycerides; HDL-C, high-density lipoprotein cholesterol; LDL-C, low-density lipoprotein cholesterol; GLU, levels and glucose; BMI, body mass index.

Table S3 Haplotype analysis of GUCY1A3 between the EH cases and controls

\begin{tabular}{|c|c|c|c|c|c|c|}
\hline Gene & Single domain & Haplotype & Case (\%) & Control (\%) & OR (95\% Cl) & $\mathrm{P}$ \\
\hline \multirow{2}{*}{ GUCY1A3 } & & $\mathrm{CC}(\mathrm{Ab})$ & 4.14 & 3.76 & $1.097(0.879-1.368)$ & 0.416 \\
\hline & & $\mathrm{TT}(\mathrm{aB})$ & 20.04 & 20.57 & $0.972(0.873-1.082)$ & 0.602 \\
\hline
\end{tabular}

$\mathrm{EH}$, essential hypertension; OR, odds ratio; $\mathrm{Cl}$, confidence interval. 
Table S4 Stratified analysis of the association between GUCY1A3/GUCY1B3 and hypertension

\begin{tabular}{|c|c|c|c|c|c|c|c|c|c|}
\hline \multirow{2}{*}{ SNPs } & \multirow{2}{*}{ Group } & \multirow{2}{*}{ Control } & \multirow{2}{*}{ Case } & \multicolumn{2}{|l|}{ Additive } & \multicolumn{2}{|l|}{ Dominate } & \multicolumn{2}{|l|}{ Recessive } \\
\hline & & & & OR (95\% Cl) & $P$ & OR (95\% Cl) & $P$ & OR $(95 \% \mathrm{Cl})$ & $\mathrm{P}$ \\
\hline \multirow[t]{2}{*}{ rs1459853 } & $<55$ years & $325 / 411 / 120$ & 212/230/92 & $1.031(0.883-1.204)$ & 0.7 & $0.93(0.745-1.16)$ & 0.519 & $1.277(0.949-1.717)$ & 0.106 \\
\hline & $\geq 55$ years & $549 / 613 / 186$ & $588 / 658 / 232$ & $1.06(0.954-1.179)$ & 0.279 & $1.04(0.895-1.209)$ & 0.609 & $1.163(0.944-1.433)$ & 0.156 \\
\hline \multirow[t]{2}{*}{ rs2229202 } & $<55$ years & $690 / 154 / 12$ & $427 / 101 / 5$ & $1.002(0.781-1.284)$ & 0.99 & $1.032(0.786-1.354)$ & 0.821 & $0.666(0.233-1.901)$ & 0.448 \\
\hline & $\geq 55$ years & $1,094 / 237 / 18$ & $1195 / 262 / 21$ & $1.018(0.859-1.205)$ & 0.84 & $1.016(0.842-1.226)$ & 0.869 & $1.066(0.565-2.009)$ & 0.844 \\
\hline \multirow[t]{2}{*}{ rs3806777 } & $<55$ years & $532 / 291 / 32$ & $350 / 159 / 23$ & $0.91(0.751-1.104)$ & 0.339 & $0.856(0.683-1.074)$ & 0.18 & $1.162(0.672-2.008)$ & 0.59 \\
\hline & $\geq 55$ years & $865 / 401 / 73$ & $938 / 475 / 62$ & $0.993(0.874-1.128)$ & 0.912 & $1.045(0.895-1.219)$ & 0.578 & $0.761(0.538-1.077)$ & 0.123 \\
\hline \multirow[t]{2}{*}{ rs3806782 } & $<55$ years & $790 / 66 / 0$ & $491 / 40 / 2$ & $1.074(0.727-1.586)$ & 0.72 & $1.024(0.684-1.532)$ & 0.909 & - & - \\
\hline & $\geq 55$ years & $1,254 / 91 / 4$ & $1360 / 110 / 6$ & $1.125(0.864-1.464)$ & 0.382 & $1.126(0.849-1.492)$ & 0.41 & $1.372(0.386-4.874)$ & 0.624 \\
\hline \multirow[t]{2}{*}{ rs3976576 } & $<55$ years & $566 / 256 / 34$ & $352 / 153 / 28$ & $1.043(0.863-1.259)$ & 0.666 & $1.004(0.799-1.261)$ & 0.975 & $1.34(0.803-2.237)$ & 0.262 \\
\hline & $\geq 55$ years & $844 / 433 / 65$ & $935 / 489 / 53$ & $0.95(0.835-1.081)$ & 0.438 & $0.982(0.843-1.145)$ & 0.821 & $0.731(0.505-1.059)$ & 0.098 \\
\hline \multirow[t]{2}{*}{ rs7698460 } & $<55$ years & $554 / 277 / 25$ & $346 / 168 / 19$ & $1.015(0.833-1.236)$ & 0.882 & $0.991(0.791-1.243)$ & 0.941 & $1.229(0.67-2.254)$ & 0.506 \\
\hline & $\geq 55$ years & $861 / 424 / 60$ & $983 / 443 / 50$ & $0.89(0.781-1.016)$ & 0.084 & $0.892(0.764-1.042)$ & 0.15 & $0.751(0.512-1.101)$ & 0.142 \\
\hline \multirow[t]{2}{*}{ rs1459853 } & Men & $369 / 399 / 115$ & $329 / 370 / 130$ & $1.104(0.963-1.266)$ & 0.156 & $1.091(0.9-1.323)$ & 0.376 & $1.242(0.947-1.629)$ & 0.117 \\
\hline & Women & $505 / 625 / 191$ & $471 / 518 / 194$ & $1.007(0.9-1.127)$ & 0.899 & $0.936(0.797-1.099)$ & 0.417 & $1.161(0.934-1.442)$ & 0.179 \\
\hline \multirow[t]{2}{*}{ rs2229202 } & Men & $720 / 150 / 12$ & $675 / 143 / 10$ & $0.998(0.8-1.245)$ & 0.984 & $1.007(0.789-1.287)$ & 0.953 & $0.886(0.381-2.063)$ & 0.779 \\
\hline & Women & $1064 / 241 / 18$ & $947 / 220 / 16$ & $1.019(0.853-1.218)$ & 0.836 & $1.024(0.841-1.247)$ & 0.815 & $0.994(0.505-1.958)$ & 0.986 \\
\hline \multirow[t]{2}{*}{ rs3806777 } & Men & $558 / 277 / 42$ & $539 / 254 / 34$ & $0.935(0.792-1.103)$ & 0.423 & $0.935(0.766-1.14)$ & 0.504 & $0.852(0.537-1.354)$ & 0.499 \\
\hline & Women & $839 / 415 / 63$ & $749 / 380 / 51$ & $0.993(0.867-1.138)$ & 0.921 & $1.01(0.858-1.189)$ & 0.905 & $0.899(0.616-1.312)$ & 0.581 \\
\hline \multirow[t]{2}{*}{ rs3806782 } & Men & $817 / 63 / 2$ & $753 / 71 / 4$ & $1.257(0.907-1.743)$ & 0.169 & $1.252(0.885-1.77)$ & 0.204 & $2.136(0.39-11.692)$ & 0.382 \\
\hline & Women & $1,227 / 94 / 2$ & $1098 / 79 / 4$ & $0.994(0.744-1.329)$ & 0.97 & $0.966(0.712-1.311)$ & 0.825 & $2.245(0.41-12.277)$ & 0.351 \\
\hline \multirow[t]{2}{*}{ rs3976576 } & Men & $566 / 275 / 40$ & $532 / 260 / 35$ & $0.988(0.837-1.166)$ & 0.888 & $0.996(0.817-1.215)$ & 0.971 & $0.929(0.584-1.478)$ & 0.756 \\
\hline & Women & $844 / 414 / 59$ & $755 / 382 / 46$ & $0.99(0.862-1.136)$ & 0.886 & $1.012(0.859-1.191)$ & 0.891 & $0.863(0.582-1.279)$ & 0.462 \\
\hline \multirow[t]{2}{*}{ rs7698460 } & Men & $581 / 270 / 30$ & $539 / 254 / 35$ & $1.055(0.89-1.25)$ & 0.536 & $1.038(0.851-1.268)$ & 0.711 & $1.252(0.762-2.058)$ & 0.376 \\
\hline & Women & $834 / 431 / 55$ & $790 / 357 / 34$ & $0.85(0.737-0.98)$ & 0.025 & $0.849(0.72-1.002)$ & 0.052 & $0.682(0.441-1.053)$ & 0.084 \\
\hline rs1459853 & Non-smoking & 654/786/232 & $614 / 672 / 246$ & $1.025(0.928-1.133)$ & 0.621 & $0.961(0.834-1.107)$ & 0.577 & $1.187(0.977-1.442)$ & 0.084 \\
\hline & Smoking & $220 / 238 / 74$ & $186 / 216 / 78$ & 1.107 (0.927-1.32) & 0.261 & $1.115(0.866-1.434)$ & 0.399 & $1.201(0.85-1.696)$ & 0.299 \\
\hline rs2229202 & Non-smoking & $1,351 / 300 / 23$ & $1,217 / 293 / 22$ & $1.07(0.915-1.252)$ & 0.396 & $1.083(0.91-1.288)$ & 0.37 & $1.046(0.581-1.884)$ & 0.881 \\
\hline & Smoking & $433 / 91 / 7$ & $405 / 70 / 4$ & $0.813(0.601-1.1)$ & 0.18 & $0.807(0.58-1.124)$ & 0.205 & $0.63(0.183-2.167)$ & 0.464 \\
\hline rs3806777 & Non-smoking & $1,073 / 512 / 79$ & $974 / 494 / 61$ & $1.001(0.886-1.13)$ & 0.991 & $1.035(0.895-1.196)$ & 0.646 & $0.834(0.592-1.173)$ & 0.297 \\
\hline & Smoking & $324 / 180 / 26$ & $314 / 140 / 24$ & $0.878(0.71-1.085)$ & 0.229 & $0.821(0.635-1.062)$ & 0.134 & $1.025(0.58-1.81)$ & 0.933 \\
\hline rs3806782 & Non-smoking & $1,560 / 110 / 3$ & $1,412 / 112 / 6$ & $1.169(0.907-1.506)$ & 0.227 & $1.154(0.883-1.508)$ & 0.295 & $2.192(0.547-8.778)$ & 0.268 \\
\hline & Smoking & $484 / 47 / 1$ & $439 / 38 / 2$ & $0.951(0.626-1.443)$ & 0.813 & $0.919(0.592-1.425)$ & 0.705 & $2.226(0.201-24.632)$ & 0.514 \\
\hline rs3976576 & Non-smoking & $1,078 / 516 / 74$ & $990 / 482 / 60$ & $0.984(0.871-1.112)$ & 0.799 & $1(0.865-1.156)$ & 0.997 & $0.878(0.62-1.243)$ & 0.463 \\
\hline & Smoking & $332 / 173 / 25$ & $297 / 160 / 21$ & $1.006(0.812-1.245)$ & 0.96 & $1.022(0.792-1.319)$ & 0.868 & $0.928(0.513-1.681)$ & 0.806 \\
\hline rs7698460 & Non-smoking & $1,067 / 535 / 68$ & $1013 / 471 / 46$ & $0.896(0.79-1.015)$ & 0.085 & $0.903(0.781-1.045)$ & 0.17 & $0.73(0.499-1.069)$ & 0.106 \\
\hline & Smoking & $348 / 166 / 17$ & $316 / 140 / 23$ & $1.038(0.833-1.293)$ & 0.742 & $0.981(0.756-1.273)$ & 0.885 & $1.525(0.805-2.891)$ & 0.196 \\
\hline rs1459853 & Non-drinking & 686/805/237 & $635 / 692 / 262$ & $1.053(0.955-1.161)$ & 0.301 & $0.989(0.861-1.137)$ & 0.877 & $1.242(1.027-1.503)$ & 0.026 \\
\hline & Drinking & $188 / 219 / 69$ & $165 / 196 / 62$ & $1.014(0.839-1.225)$ & 0.888 & $1.021(0.781-1.335)$ & 0.881 & $1.013(0.699-1.468)$ & 0.945 \\
\hline rs2229202 & Non-drinking & $1,392 / 313 / 25$ & $1,269 / 298 / 22$ & $1.028(0.881-1.199)$ & 0.725 & $1.039(0.875-1.232)$ & 0.664 & $0.957(0.538-1.705)$ & 0.883 \\
\hline & Drinking & $392 / 78 / 5$ & $353 / 65 / 4$ & $0.929(0.674-1.281)$ & 0.654 & $0.923(0.65-1.31)$ & 0.655 & $0.9(0.24-3.372)$ & 0.875 \\
\hline rs3806777 & Non-drinking & $1,101 / 543 / 77$ & $1,016 / 503 / 67$ & $0.99(0.879-1.115)$ & 0.866 & $0.996(0.864-1.148)$ & 0.959 & $0.942(0.674-1.316)$ & 0.725 \\
\hline & Drinking & $296 / 149 / 28$ & $272 / 131 / 18$ & $0.899(0.718-1.125)$ & 0.352 & $0.916(0.697-1.204)$ & 0.529 & $0.71(0.387-1.303)$ & 0.269 \\
\hline rs3806782 & Non-drinking & $1609 / 118 / 2$ & $1465 / 115 / 7$ & $1.153(0.899-1.477)$ & 0.262 & $1.117(0.859-1.451)$ & 0.409 & $3.826(0.794-18.443)$ & 0.095 \\
\hline & Drinking & $435 / 39 / 2$ & $386 / 35 / 1$ & $0.97(0.623-1.51)$ & 0.893 & $0.99(0.62-1.58)$ & 0.965 & $0.563(0.051-6.231)$ & 0.639 \\
\hline rs3976576 & Non-drinking & $1107 / 537 / 80$ & $1011 / 513 / 65$ & $1.001(0.889-1.128)$ & 0.985 & $1.026(0.89-1.182)$ & 0.726 & $0.876(0.627-1.225)$ & 0.44 \\
\hline & Drinking & $303 / 152 / 19$ & $276 / 129 / 16$ & $0.943(0.747-1.192)$ & 0.625 & $0.931(0.707-1.225)$ & 0.61 & $0.946(0.48-1.864)$ & 0.873 \\
\hline rs7698460 & Non-drinking & $1107 / 549 / 71$ & $1063 / 469 / 55$ & $0.893(0.79-1.009)$ & 0.07 & $0.88(0.762-1.016)$ & 0.081 & $0.837(0.585-1.199)$ & 0.332 \\
\hline & Drinking & $308 / 152 / 14$ & $266 / 142 / 14$ & $1.08(0.85-1.372)$ & 0.529 & $1.088(0.828-1.43)$ & 0.545 & $1.127(0.531-2.393)$ & 0.755 \\
\hline
\end{tabular}

SNPs, single nucleotide polymorphisms; OR, odds ratio; $\mathrm{Cl}$, confidence interval. 
Table S5 Association analyses of GUCY1A3/GUCY1B3 and hypertension incidence in the follow-up study

\begin{tabular}{|c|c|c|c|c|c|c|c|c|}
\hline \multirow{2}{*}{ SNPs } & \multirow{2}{*}{$\begin{array}{l}\text { Gene } \\
\text { type }\end{array}$} & \multirow{2}{*}{$\mathrm{n}$} & \multicolumn{3}{|c|}{$\mathrm{HR}(95 \% \mathrm{Cl})$} & \multicolumn{3}{|c|}{$\mathrm{HR}(95 \% \mathrm{Cl})^{\mathrm{a}}$} \\
\hline & & & Additive & Dominate & Recessive & Additive & Dominate & Recessive \\
\hline \multirow[t]{3}{*}{ rs1459853 } & GG & 226 & $1.04(0.928-1.166)$ & $1.124(0.954-1.325)$ & $0.932(0.74-1.173)$ & 1.025 (0.913-1.15) & 1.099 (0.931-1.298) & $0.918(0.727-1.158)$ \\
\hline & GA & 302 & $P=0.497$ & $P=0.163$ & $P=0.548$ & $P=0.677$ & $P=0.264$ & $P=0.470$ \\
\hline & $\mathrm{AA}$ & 84 & & & & & & \\
\hline \multirow[t]{3}{*}{ rs2229202 } & $\mathrm{CC}$ & 491 & $1.121(0.938-1.339)$ & $1.106(0.907-1.349)$ & $1.512(0.833-2.747)$ & $1.126(0.94-1.35)$ & $1.096(0.898-1.339)$ & $1.784(0.978-3.252)$ \\
\hline & CT & 111 & $P=0.209$ & $P=0.318$ & $P=0.174$ & $P=0.197$ & $P=0.367$ & $P=0.059$ \\
\hline & $\pi$ & 11 & & & & & & \\
\hline \multirow[t]{3}{*}{ rs3806777 } & $\mathrm{CC}$ & 393 & $0.984(0.854-1.133)$ & $0.968(0.821-1.142)$ & $1.062(0.711-1.585)$ & $0.995(0.865-1.145)$ & $0.991(0.84-1.17)$ & $1.013(0.678-1.513)$ \\
\hline & CT & 194 & $P=0.821$ & $\mathrm{P}=0.702$ & $\mathrm{P}=0.770$ & $P=0.946$ & $P=0.917$ & $P=0.951$ \\
\hline & $\pi$ & 25 & & & & & & \\
\hline \multirow[t]{3}{*}{ rs3806782 } & $\pi$ & 568 & $0.907(0.675-1.22)$ & 0.878 (0.646-1.194) & 2.304 (0.574-9.243) & $0.988(0.735-1.328)$ & $0.962(0.707-1.308)$ & $2.23(0.551-9.028)$ \\
\hline & $\mathrm{TC}$ & 42 & $P=0.520$ & $P=0.408$ & $\mathrm{P}=0.239$ & $P=0.938$ & $P=0.803$ & $P=0.261$ \\
\hline & $\mathrm{CC}$ & 2 & & & & & & \\
\hline \multirow[t]{3}{*}{ rs3976576 } & $\pi$ & 407 & 0.912 (0.79-1.053) & $0.904(0.765-1.069)$ & $0.848(0.554-1.298)$ & $0.924(0.8-1.068)$ & $0.914(0.773-1.081)$ & $0.892(0.581-1.367)$ \\
\hline & $\mathrm{TC}$ & 184 & $P=0.208$ & $P=0.239$ & $P=0.448$ & $\mathrm{P}=0.284$ & $P=0.295$ & $P=0.599$ \\
\hline & $\mathrm{CC}$ & 22 & & & & & & \\
\hline \multirow[t]{3}{*}{ rs7698460 } & GG & 393 & $0.992(0.863-1.142)$ & $1.011(0.857-1.193)$ & $0.873(0.57-1.336)$ & $0.977(0.85-1.122)$ & $1.011(0.857-1.194)$ & $0.766(0.499-1.176)$ \\
\hline & GA & 197 & $\mathrm{P}=0.914$ & $P=0.895$ & $P=0.531$ & $P=0.740$ & $P=0.894$ & $P=0.223$ \\
\hline & $\mathrm{AA}$ & 22 & & & & & & \\
\hline
\end{tabular}

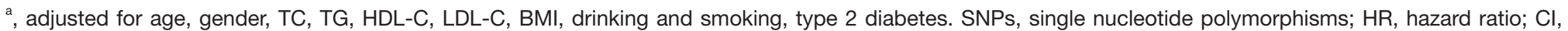

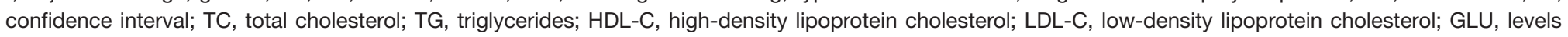
and glucose; BMI, body mass index. 
Table S6 Stratified analyses of the association between GUCY1A3/GUCY1B3 and hypertension incidence in the follow-up study

\begin{tabular}{|c|c|c|c|c|c|c|c|c|}
\hline \multirow{2}{*}{ SNPs } & \multirow{2}{*}{ Group } & \multirow{2}{*}{ WT/HT/MT } & \multicolumn{2}{|l|}{ Additive } & \multicolumn{2}{|c|}{ Dominate } & \multicolumn{2}{|l|}{ Recessive } \\
\hline & & & $\mathrm{HR}(95 \% \mathrm{Cl})$ & $\mathrm{P}$ & $\mathrm{HR}(95 \% \mathrm{Cl})$ & $\mathrm{P}$ & HR (95\% Cl) & $\mathrm{P}$ \\
\hline \multirow[t]{2}{*}{ rs1459853 } & $<55$ years & $59 / 97 / 27$ & $1.13(0.917-1.393)$ & 0.251 & $1.288(0.945-1.757)$ & 0.109 & $1.005(0.666-1.517)$ & 0.979 \\
\hline & $\geq 55$ years & $167 / 205 / 57$ & $1.026(0.896-1.175)$ & 0.708 & $1.104(0.909-1.341)$ & 0.318 & $0.91(0.689-1.204)$ & 0.51 \\
\hline \multirow[t]{2}{*}{ rs2229202 } & $<55$ years & $154 / 25 / 4$ & $0.933(0.657-1.324)$ & 0.696 & $0.866(0.581-1.29)$ & 0.48 & $1.543(0.572-4.164)$ & 0.391 \\
\hline & $\geq 55$ years & $337 / 86 / 7$ & $1.236(1.003-1.522)$ & 0.046 & $1.233(0.98-1.552)$ & 0.074 & $1.727(0.818-3.648)$ & 0.152 \\
\hline \multirow[t]{2}{*}{ rs3806777 } & $<55$ years & $112 / 65 / 6$ & $1.089(0.835-1.422)$ & 0.528 & $1.065(0.791-1.434)$ & 0.677 & $1.456(0.643-3.295)$ & 0.367 \\
\hline & $\geq 55$ years & $281 / 129 / 19$ & $0.936(0.794-1.104)$ & 0.434 & $0.936(0.766-1.142)$ & 0.513 & $0.856(0.54-1.357)$ & 0.508 \\
\hline \multirow[t]{2}{*}{ rs3806782 } & $<55$ years & $172 / 11 / 0$ & $0.62(0.337-1.143)$ & 0.126 & $0.62(0.337-1.143)$ & 0.126 & - & - \\
\hline & $\geq 55$ years & $396 / 31 / 2$ & $1.088(0.78-1.518)$ & 0.62 & $1.066(0.747-1.521)$ & 0.725 & $1.845(0.459-7.409)$ & 0.388 \\
\hline \multirow[t]{2}{*}{ rs3976576 } & $<55$ years & $122 / 56 / 5$ & $0.895(0.685-1.17)$ & 0.417 & $0.9(0.662-1.225)$ & 0.503 & $0.727(0.298-1.77)$ & 0.482 \\
\hline & $\geq 55$ years & $285 / 128 / 17$ & $0.919(0.775-1.088)$ & 0.326 & $0.906(0.741-1.107)$ & 0.334 & $0.887(0.546-1.442)$ & 0.63 \\
\hline \multirow[t]{2}{*}{ rs7698460 } & $<55$ years & $115 / 64 / 4$ & $0.965(0.742-1.256)$ & 0.791 & $1.01(0.748-1.365)$ & 0.946 & $0.611(0.226-1.652)$ & 0.331 \\
\hline & $\geq 55$ years & $278 / 133 / 18$ & $0.994(0.844-1.171)$ & 0.942 & $1.02(0.837-1.244)$ & 0.845 & $0.859(0.535-1.378)$ & 0.528 \\
\hline \multirow[t]{2}{*}{ rs1459853 } & Men & $98 / 127 / 41$ & $1.169(0.985-1.387)$ & 0.074 & $1.267(0.986-1.627)$ & 0.064 & $1.17(0.838-1.633)$ & 0.356 \\
\hline & Women & $128 / 175 / 43$ & $0.958(0.822-1.117)$ & 0.584 & $1.04(0.835-1.295)$ & 0.727 & $0.781(0.567-1.075)$ & 0.13 \\
\hline \multirow[t]{2}{*}{ rs2229202 } & Men & $207 / 52 / 7$ & $1.426(1.097-1.854)$ & 0.008 & $1.342(1.003-1.795)$ & 0.048 & $3.926(1.848-8.343)$ & $<0.001$ \\
\hline & Women & $284 / 59 / 4$ & $0.944(0.738-1.207)$ & 0.645 & $0.955(0.727-1.255)$ & 0.743 & $0.739(0.276-1.981)$ & 0.548 \\
\hline \multirow[t]{2}{*}{ rs3806777 } & Men & $176 / 80 / 10$ & $0.905(0.726-1.129)$ & 0.376 & $0.873(0.677-1.127)$ & 0.297 & $1.011(0.537-1.903)$ & 0.974 \\
\hline & Women & $217 / 114 / 15$ & $1.046(0.87-1.258)$ & 0.629 & $1.047(0.842-1.302)$ & 0.679 & $1.106(0.658-1.857)$ & 0.704 \\
\hline \multirow[t]{2}{*}{ rs3806782 } & Men & $246 / 19 / 1$ & $1.017(0.663-1.559)$ & 0.94 & $1.01(0.64-1.594)$ & 0.968 & - & - \\
\hline & Women & $322 / 23 / 1$ & $0.83(0.552-1.249)$ & 0.372 & $0.795(0.524-1.207)$ & 0.282 & - & - \\
\hline \multirow[t]{2}{*}{ rs3976576 } & Men & $171 / 84 / 11$ & $1.007(0.813-1.246)$ & 0.95 & $0.999(0.777-1.284)$ & 0.992 & $1.065(0.582-1.951)$ & 0.837 \\
\hline & Women & $236 / 100 / 11$ & $0.845(0.696-1.026)$ & 0.089 & $0.836(0.667-1.048)$ & 0.12 & $0.71(0.389-1.295)$ & 0.265 \\
\hline \multirow[t]{2}{*}{ rs7698460 } & Men & $180 / 77 / 9$ & $0.902(0.723-1.125)$ & 0.362 & $0.89(0.688-1.15)$ & 0.372 & $0.858(0.441-1.67)$ & 0.653 \\
\hline & Women & $213 / 120 / 13$ & $1.058(0.882-1.27)$ & 0.542 & $1.103(0.888-1.37)$ & 0.376 & $0.895(0.514-1.558)$ & 0.695 \\
\hline \multirow[t]{2}{*}{ rs1459853 } & Non-smoking & $167 / 228 / 58$ & $1.029(0.901-1.175)$ & 0.676 & $1.136(0.939-1.376)$ & 0.19 & $0.869(0.659-1.144)$ & 0.317 \\
\hline & Smoking & $59 / 74 / 26$ & $1.1(0.881-1.374)$ & 0.398 & $1.143(0.826-1.582)$ & 0.42 & $1.125(0.738-1.715)$ & 0.585 \\
\hline \multirow[t]{2}{*}{ rs2229202 } & Non-smoking & $368 / 80 / 6$ & $1.014(0.821-1.252)$ & 0.899 & $1.021(0.807-1.291)$ & 0.863 & $0.958(0.428-2.144)$ & 0.916 \\
\hline & Smoking & $123 / 31 / 5$ & $1.504(1.077-2.101)$ & 0.017 & $1.393(0.958-2.026)$ & 0.083 & $4.625(1.889-11.325)$ & 0.001 \\
\hline rs3806777 & Non-smoking & $289 / 147 / 17$ & $1.01(0.857-1.19)$ & 0.907 & $1.013(0.837-1.228)$ & 0.891 & $0.999(0.615-1.623)$ & 0.998 \\
\hline & Smoking & $104 / 47 / 8$ & $0.944(0.713-1.249)$ & 0.685 & $0.884(0.636-1.229)$ & 0.462 & $1.258(0.617-2.565)$ & 0.528 \\
\hline rs3806782 & Non-smoking & $422 / 29 / 2$ & $0.887(0.625-1.26)$ & 0.504 & $0.839(0.582-1.209)$ & 0.347 & $3.954(0.984-15.882)$ & 0.053 \\
\hline & Smoking & $146 / 13 / 0$ & $1.015(0.583-1.767)$ & 0.957 & $1.045(0.591-1.848)$ & 0.879 & - & - \\
\hline rs3976576 & Non-smoking & $308 / 130 / 16$ & $0.898(0.759-1.062)$ & 0.21 & $0.887(0.729-1.081)$ & 0.235 & $0.831(0.505-1.37)$ & 0.469 \\
\hline & Smoking & $99 / 54 / 6$ & $0.96(0.73-1.264)$ & 0.772 & $0.962(0.697-1.326)$ & 0.812 & $0.9(0.398-2.039)$ & 0.801 \\
\hline rs7698460 & Non-smoking & $283 / 152 / 18$ & $1.048(0.895-1.229)$ & 0.559 & $1.088(0.9-1.316)$ & 0.384 & $0.907(0.566-1.454)$ & 0.685 \\
\hline & Smoking & $110 / 45 / 4$ & $0.823(0.61-1.11)$ & 0.201 & $0.805(0.575-1.128)$ & 0.208 & $0.75(0.277-2.029)$ & 0.571 \\
\hline rs1459853 & Non-drinking & $168 / 229 / 60$ & $1.043(0.915-1.189)$ & 0.526 & $1.166(0.964-1.411)$ & 0.113 & $0.877(0.668-1.151)$ & 0.343 \\
\hline & Drinking & $58 / 73 / 24$ & $1.015(0.806-1.28)$ & 0.897 & $0.983(0.71-1.363)$ & 0.92 & $1.091(0.705-1.689)$ & 0.696 \\
\hline rs2229202 & Non-drinking & $363 / 88 / 7$ & $1.122(0.917-1.373)$ & 0.264 & $1.141(0.91-1.43)$ & 0.254 & $1.135(0.538-2.396)$ & 0.739 \\
\hline & Drinking & $128 / 23 / 4$ & $1.122(0.771-1.633)$ & 0.548 & $1.006(0.663-1.527)$ & 0.977 & $3.617(1.335-9.797)$ & 0.011 \\
\hline rs3806777 & Non-drinking & $291 / 149 / 17$ & $0.965(0.82-1.136)$ & 0.673 & $0.967(0.799-1.171)$ & 0.733 & $0.91(0.56-1.478)$ & 0.703 \\
\hline & Drinking & $102 / 45 / 8$ & $1.05(0.788-1.399)$ & 0.74 & $0.975(0.697-1.362)$ & 0.88 & $1.684(0.823-3.446)$ & 0.154 \\
\hline rs3806782 & Non-drinking & $428 / 28 / 1$ & $0.791(0.546-1.145)$ & 0.215 & $0.763(0.524-1.113)$ & 0.16 & - & - \\
\hline & Drinking & $140 / 14 / 1$ & $1.216(0.75-1.973)$ & 0.427 & $1.243(0.728-2.122)$ & 0.426 & - & - \\
\hline rs3976576 & Non-drinking & $305 / 136 / 17$ & $0.92(0.78-1.084)$ & 0.318 & $0.918(0.756-1.115)$ & 0.387 & $0.826(0.509-1.341)$ & 0.44 \\
\hline & Drinking & $102 / 48 / 5$ & $0.885(0.66-1.185)$ & 0.411 & $0.86(0.616-1.199)$ & 0.373 & $0.936(0.383-2.284)$ & 0.884 \\
\hline rs7698460 & Non-drinking & $282 / 156 / 19$ & $1.067(0.912-1.249)$ & 0.419 & $1.103(0.914-1.332)$ & 0.308 & $0.967(0.611-1.532)$ & 0.888 \\
\hline & Drinking & $111 / 41 / 3$ & $0.774(0.567-1.056)$ & 0.106 & $0.769(0.542-1.09)$ & 0.14 & $0.544(0.173-1.71)$ & 0.298 \\
\hline
\end{tabular}

SNPs, single nucleotide polymorphisms; HR, hazard ratio; $\mathrm{Cl}$, confidence interval. 
Table S7 Association analyses of rs2229202 in GUCY1B3 with hypertension in adolescents

\begin{tabular}{lcccccccc}
\hline \multirow{2}{*}{ SNPs } & Group & MM/Mm/mm & \multicolumn{5}{c}{ OR (95\% Cl) } \\
\cline { 4 - 9 } rs2229202 & Normal & $2,180 / 563 / 218$ & Addictive & P & Dominate & P & Recessive & P \\
& Pre-HT & $191 / 65 / 26$ & $1.213(1.007-1.462)$ & 0.042 & $1.33(1.023-1.729)$ & 0.033 & $1.278(0.834-1.957)$ & 0.260 \\
& HT & $193 / 78 / 23$ & $1.232(1.027-1.478)$ & 0.024 & $1.461(1.133-1.884)$ & 0.003 & $1.068(0.683-1.671)$ & 0.774 \\
& Pre-HT + HT & $384 / 143 / 49$ & $1.223(1.067-1.402)$ & 0.004 & $1.396(1.152-1.69)$ & 0.001 & $1.17(0.846-1.617)$ & 0.342 \\
\hline
\end{tabular}

The OR values were compared with those in normal group. SNPs, single nucleotide polymorphisms; M, major allele; m, minor allele; OR, odds ratio; $\mathrm{Cl}$, confidence interval; $\mathrm{HT}$, hypertension.

Table S8 Association analyses of 6 SNPs in GUCY1A3/GUCY1B3 with hypertension in adolescents

\begin{tabular}{|c|c|c|c|c|c|c|c|c|}
\hline SNPs & Group & $\mathrm{MM} / \mathrm{Mm} / \mathrm{mm}$ & \multicolumn{6}{|c|}{ OR $(95 \% \mathrm{Cl})$} \\
\hline \multirow[t]{3}{*}{ rs1459853 } & Normal & $903 / 1291 / 780$ & 1 & & 1 & & 1 & \\
\hline & Pre-HT & $72 / 134 / 76$ & $1.104(0.938-1.299)$ & 0.235 & $1.272(0.962-1.681)$ & 0.091 & $1.038(0.788-1.367)$ & 0.792 \\
\hline & HT & $81 / 122 / 91$ & $1.143(0.974-1.341)$ & 0.101 & $1.147(0.877-1.498)$ & 0.316 & $1.261(0.972-1.636)$ & 0.081 \\
\hline \multirow[t]{4}{*}{ rs2229202 } & Normal & $2,180 / 563 / 218$ & 1 & & 1 & & 1 & \\
\hline & Pre-HT & $191 / 65 / 26$ & $1.213(1.007-1.462)$ & 0.042 & 1.33 (1.023-1.729) & 0.033 & $1.278(0.834-1.957)$ & 0.260 \\
\hline & HT & $193 / 78 / 23$ & $1.232(1.027-1.478)$ & 0.024 & $1.461(1.133-1.884)$ & 0.003 & $1.068(0.683-1.671)$ & 0.774 \\
\hline & Pre-HT + HT & $384 / 143 / 49$ & $1.223(1.067-1.402)$ & 0.004 & $1.396(1.152-1.69)$ & 0.001 & $1.17(0.846-1.617)$ & 0.342 \\
\hline \multirow{2}{*}{ rs3806777 } & HT & $184 / 95 / 14$ & $0.88(0.723-1.07)$ & 0.200 & $0.921(0.719-1.181)$ & 0.517 & $0.592(0.34-1.029)$ & 0.063 \\
\hline & Pre-HT + HT & $353 / 181 / 41$ & $0.97(0.842-1.118)$ & 0.675 & $0.978(0.814-1.175)$ & 0.812 & $0.906(0.642-1.279)$ & 0.574 \\
\hline \multirow[t]{4}{*}{ rs3806782 } & Normal & $2,722 / 218 / 28$ & 1 & & 1 & & 1 & \\
\hline & Pre-HT & $259 / 21 / 2$ & $0.964(0.651-1.426)$ & 0.853 & $0.983(0.629-1.535)$ & 0.939 & $0.75(0.178-3.165)$ & 0.695 \\
\hline & HT & $263 / 30 / 1$ & $1.162(0.819-1.648)$ & 0.399 & $1.304(0.879-1.935)$ & 0.187 & $0.358(0.049-2.643)$ & 0.314 \\
\hline & Pre-HT + HT & $522 / 51 / 3$ & $1.065(0.811-1.399)$ & 0.648 & $1.145(0.84-1.559)$ & 0.392 & $0.55(0.167-1.814)$ & 0.326 \\
\hline \multirow[t]{2}{*}{ rs7698460 } & Normal & $1,890 / 968 / 108$ & 1 & & 1 & & 1 & \\
\hline & Pre-HT & $179 / 95 / 8$ & $0.982(0.788-1.224)$ & 0.873 & $1.011(0.784-1.303)$ & 0.934 & $0.773(0.373-1.601)$ & 0.488 \\
\hline rs3796576 & Pre-HT + HT & $348 / 194 / 30$ & $1.063(0.912-1.239)$ & 0.435 & $1.051(0.875-1.263)$ & 0.594 & $1.213(0.807-1.824)$ & 0.352 \\
\hline
\end{tabular}

The OR values were compared with the normal group. SNPs, single nucleotide polymorphisms; M, major allele; m, minor allele; OR, odds ratio; $\mathrm{Cl}$, confidence interval; $\mathrm{HT}$, hypertension. 
Table S9 Association of 6 SNPs in GUCY1A3/GUCY1B3 with hypertension in adolescents after adjust for covariates

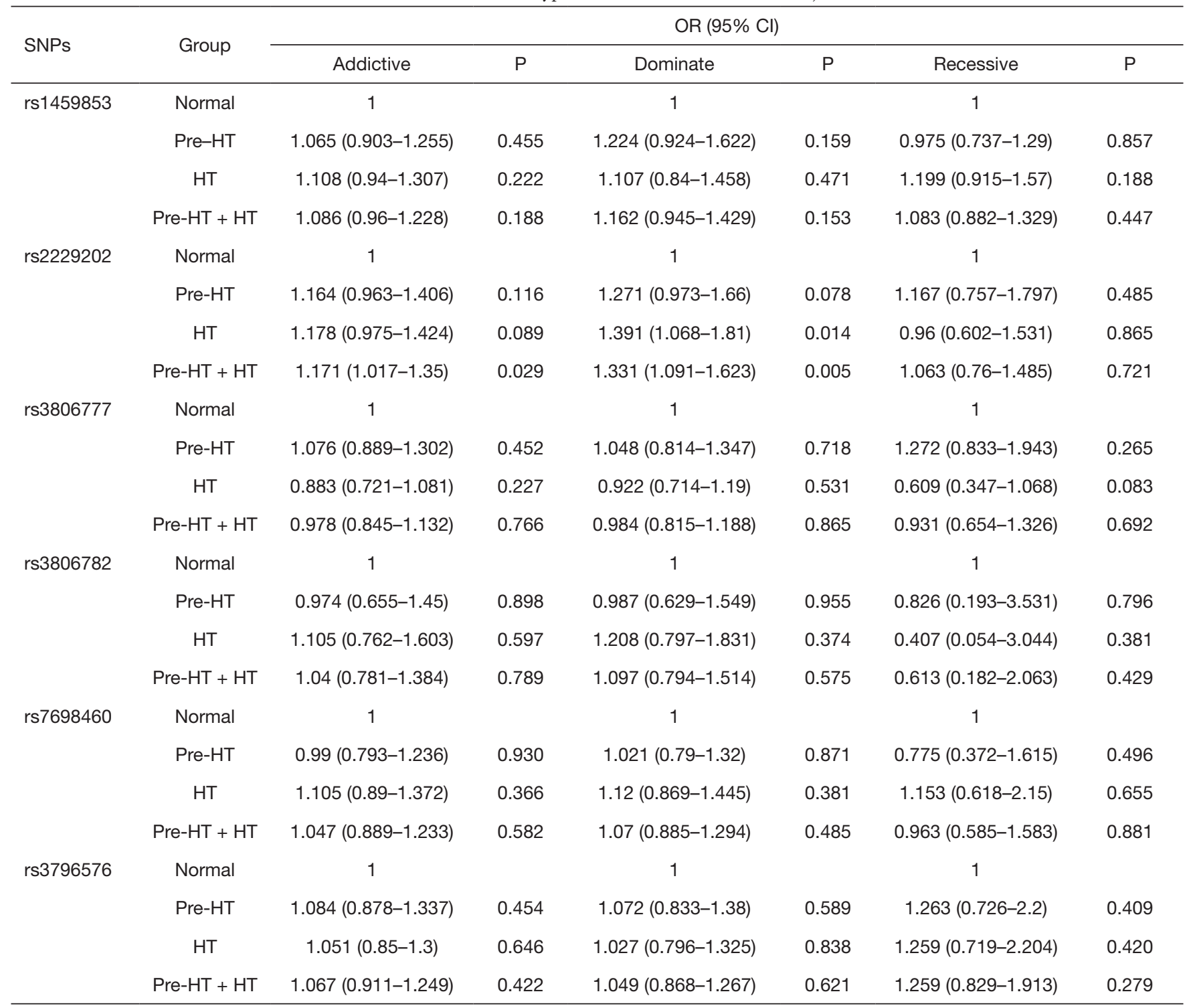

Adjusted for age, gender, TC, TG, HDL-C, LDL-C, BMI. SNPs, single nucleotide polymorphisms; M, major allele; m, minor allele; OR, odds ratio; $\mathrm{Cl}$, confidence interval; $\mathrm{HT}$, hypertension; TC, total cholesterol; TG, triglycerides; HDL-C, high-density lipoprotein cholesterol; LDL-C, low-density lipoprotein cholesterol; BMI, body mass index. 
Table S10 Stratification analyses by gender for association of 6 SNPs in GUCY1A3/GUCY1B3 with hypertension in adolescents

\begin{tabular}{|c|c|c|c|c|c|c|c|c|c|}
\hline \multirow{2}{*}{ SNPs } & \multirow{2}{*}{ Gender } & \multirow{2}{*}{ Group } & \multirow{2}{*}{$\mathrm{MM} / \mathrm{Mm} / \mathrm{mm}$} & \multicolumn{6}{|c|}{ OR (95\% Cl) } \\
\hline & & & & Addictive & $\mathrm{P}$ & Dominate & $\mathrm{P}$ & Recessive & $\mathrm{P}$ \\
\hline \multirow[t]{8}{*}{ rs1459853 } & Boys & Normal & $467 / 656 / 403$ & 1 & & 1 & & 1 & \\
\hline & & Pre-HT & $38 / 61 / 35$ & $1.035(0.818-1.31)$ & 0.772 & $1.114(0.753-1.647)$ & 0.588 & $0.985(0.659-1.472)$ & 0.942 \\
\hline & & $\mathrm{HT}$ & $37 / 70 / 41$ & $1.13(0.903-1.415)$ & 0.286 & $1.323(0.898-1.949)$ & 0.157 & $1.068(0.732-1.558)$ & 0.734 \\
\hline & & Pre-HT + HT & $75 / 131 / 76$ & $1.084(0.915-1.284)$ & 0.350 & $1.217(0.915-1.62)$ & 0.178 & $1.028(0.772-1.369)$ & 0.850 \\
\hline & Girls & Normal & $436 / 635 / 377$ & 1 & & 1 & & 1 & \\
\hline & & Pre-HT & $34 / 73 / 41$ & $1.169(0.933-1.466)$ & 0.174 & $1.445(0.969-2.153)$ & 0.071 & $1.089(0.745-1.59)$ & 0.661 \\
\hline & & HT & $44 / 52 / 50$ & $1.157(0.922-1.451)$ & 0.209 & $0.999(0.689-1.447)$ & 0.995 & $1.48(1.031-2.124)$ & 0.034 \\
\hline & & Pre-HT + HT & $78 / 125 / 91$ & $1.163(0.984-1.375)$ & 0.077 & $1.193(0.9-1.582)$ & 0.220 & $1.273(0.969-1.674)$ & 0.083 \\
\hline \multirow[t]{9}{*}{ rs2229202 } & Boys & Normal & $1,118 / 286 / 114$ & 1 & & 1 & & 1 & \\
\hline & & Pre-HT & $89 / 31 / 14$ & $1.283(0.984-1.672)$ & 0.065 & $1.413(0.97-2.059)$ & 0.072 & $1.437(0.8-2.58)$ & 0.225 \\
\hline & & $\mathrm{HT}$ & $92 / 50 / 6$ & $1.223(0.945-1.582)$ & 0.126 & $1.701(1.197-2.417)$ & 0.003 & $0.52(0.225-1.204)$ & 0.127 \\
\hline & & Pre-HT + HT & $181 / 81 / 20$ & $1.251(1.031-1.519)$ & 0.024 & $1.56(1.192-2.041)$ & 0.001 & $0.94(0.574-1.539)$ & 0.806 \\
\hline & Girls & Normal & $1,062 / 277 / 104$ & 1 & & 1 & & 1 & \\
\hline & & Pre-HT & $102 / 34 / 12$ & $1.152(0.886-1.498)$ & 0.291 & $1.257(0.871-1.815)$ & 0.222 & $1.136(0.609-2.118)$ & 0.688 \\
\hline & & $\mathrm{HT}$ & $101 / 28 / 17$ & $1.242(0.961-1.605)$ & 0.098 & $1.242(0.858-1.798)$ & 0.251 & $1.697(0.985-2.922)$ & 0.057 \\
\hline & & Pre-HT + HT & $203 / 62 / 29$ & $1.197(0.987-1.452)$ & 0.068 & $1.25(0.95-1.643)$ & 0.110 & $1.409(0.915-2.171)$ & 0.120 \\
\hline & Boys & Normal & $935 / 479 / 112$ & 1 & & 1 & & 1 & \\
\hline \multirow[t]{7}{*}{ rs3806777 } & & Pre-HT & $82 / 41 / 11$ & $1.024(0.774-1.354)$ & 0.867 & $1.003(0.698-1.441)$ & 0.986 & $1.129(0.592-2.154)$ & 0.713 \\
\hline & & $\mathrm{HT}$ & $89 / 50 / 8$ & $0.97(0.739-1.274)$ & 0.829 & $1.031(0.729-1.458)$ & 0.863 & $0.727(0.347-1.52)$ & 0.396 \\
\hline & & Pre-HT + HT & $171 / 91 / 19$ & $0.996(0.813-1.22)$ & 0.969 & $1.018(0.784-1.321)$ & 0.895 & $0.916(0.553-1.515)$ & 0.731 \\
\hline & Girls & Normal & $872 / 451 / 120$ & 1 & & 1 & & 1 & \\
\hline & & Pre-HT & $87 / 45 / 16$ & $1.102(0.853-1.422)$ & 0.458 & $1.071(0.759-1.51)$ & 0.697 & $1.336(0.77-2.32)$ & 0.303 \\
\hline & & $\mathrm{HT}$ & $95 / 45 / 6$ & $0.794(0.598-1.056)$ & 0.113 & $0.82(0.574-1.171)$ & 0.274 & $0.473(0.204-1.093)$ & 0.080 \\
\hline & & Pre-HT + HT & $182 / 90 / 22$ & $0.945(0.775-1.151)$ & 0.575 & $0.94(0.726-1.216)$ & 0.637 & $0.892(0.556-1.431)$ & 0.635 \\
\hline \multirow[t]{8}{*}{ rs3806782 } & Boys & Normal & $1,375 / 132 / 16$ & 1 & & 1 & & 1 & \\
\hline & & Pre-HT & $124 / 9 / 1$ & $0.776(0.43-1.402)$ & 0.401 & $0.749(0.385-1.459)$ & 0.396 & $0.708(0.093-5.382)$ & 0.739 \\
\hline & & $\mathrm{HT}$ & $135 / 13 / 0$ & $0.827(0.479-1.428)$ & 0.496 & $0.895(0.494-1.62)$ & 0.713 & / & l \\
\hline & & Pre-HT + HT & $259 / 22 / 1$ & $0.803(0.531-1.215)$ & 0.300 & $0.825(0.521-1.305)$ & 0.411 & $0.335(0.044-2.538)$ & 0.290 \\
\hline & Girls & Normal & $1,347 / 86 / 12$ & 1 & & 1 & & 1 & \\
\hline & & Pre-HT & $135 / 12 / 1$ & $1.216(0.718-2.058)$ & 0.467 & $1.324(0.723-2.424)$ & 0.364 & $0.812(0.105-6.292)$ & 0.842 \\
\hline & & $\mathrm{HT}$ & $128 / 17 / 1$ & $1.614(1.019-2.556)$ & 0.041 & $1.933(1.133-3.298)$ & 0.016 & $0.824(0.106-6.379)$ & 0.853 \\
\hline & & Pre-HT + HT & $263 / 29 / 2$ & $1.416(0.98-2.045)$ & 0.064 & $1.62(1.059-2.478)$ & 0.026 & $0.818(0.182-3.674)$ & 0.793 \\
\hline \multirow[t]{8}{*}{ rs7698460 } & Boys & Normal & $942 / 516 / 63$ & 1 & & 1 & & 1 & \\
\hline & & Pre-HT & $82 / 47 / 5$ & $1.01(0.742-1.376)$ & 0.949 & $1.032(0.718-1.483)$ & 0.866 & $0.897(0.355-2.27)$ & 0.818 \\
\hline & & HT & $93 / 49 / 5$ & $0.937(0.693-1.267)$ & 0.674 & $0.945(0.665-1.342)$ & 0.751 & $0.815(0.323-2.059)$ & 0.665 \\
\hline & & Pre-HT + HT & $175 / 96 / 10$ & $0.972(0.776-1.216)$ & 0.802 & $0.985(0.758-1.281)$ & 0.913 & $0.854(0.433-1.685)$ & 0.649 \\
\hline & Girls & Normal & $948 / 452 / 45$ & 1 & & 1 & & 1 & \\
\hline & & Pre-HT & $97 / 48 / 3$ & $0.966(0.705-1.322)$ & 0.827 & $1.003(0.703-1.432)$ & 0.987 & $0.644(0.198-2.097)$ & 0.465 \\
\hline & & $\mathrm{HT}$ & $88 / 51 / 7$ & $1.249(0.929-1.68)$ & 0.141 & $1.257(0.887-1.782)$ & 0.198 & $1.567(0.693-3.54)$ & 0.280 \\
\hline & & Pre-HT + HT & $185 / 99 / 10$ & $1.102(0.88-1.381)$ & 0.396 & $1.124(0.866-1.458)$ & 0.379 & $1.095(0.546-2.199)$ & 0.798 \\
\hline \multirow[t]{8}{*}{ rs3796576 } & Boys & Normal & $936 / 518 / 64$ & 1 & & 1 & & 1 & \\
\hline & & Pre-HT & $86 / 42 / 5$ & $0.897(0.653-1.233)$ & 0.504 & $0.879(0.607-1.273)$ & 0.495 & $0.887(0.351-2.244)$ & 0.801 \\
\hline & & $\mathrm{HT}$ & $88 / 51 / 7$ & $1.06(0.792-1.42)$ & 0.693 & $1.06(0.749-1.5)$ & 0.742 & $1.144(0.514-2.545)$ & 0.741 \\
\hline & & Pre-HT + HT & $174 / 93 / 12$ & $0.981(0.785-1.227)$ & 0.868 & $0.97(0.746-1.263)$ & 0.824 & $1.021(0.544-1.918)$ & 0.948 \\
\hline & Girls & Normal & $898 / 476 / 65$ & 1 & & 1 & & 1 & \\
\hline & & Pre-HT & $84 / 54 / 10$ & $1.247(0.945-1.644)$ & 0.118 & $1.265(0.898-1.781)$ & 0.179 & $1.532(0.77-3.049)$ & 0.225 \\
\hline & & $\mathrm{HT}$ & $90 / 47 / 8$ & $1.04(0.777-1.392)$ & 0.792 & $1.014(0.713-1.442)$ & 0.937 & $1.234(0.58-2.626)$ & 0.585 \\
\hline & & Pre-HT + HT & $174 / 101 / 18$ & $1.142(0.926-1.409)$ & 0.215 & $1.135(0.878-1.467)$ & 0.332 & $1.384(0.808-2.369)$ & 0.237 \\
\hline
\end{tabular}

The OR values were compared with the normal group. SNPs, single nucleotide polymorphisms; M, major allele; m, minor allele; OR, odds ratio; $\mathrm{Cl}$, confidence interval; $\mathrm{HT}$, hypertension. 
Table S11 Stratification analyses by gender for association of 6 SNPs in GUCY1A3/GUCY1B3 with hypertension in adolescents after adjust for covariates

\begin{tabular}{|c|c|c|c|c|c|c|c|c|}
\hline \multirow{2}{*}{ SNPs } & \multirow{2}{*}{ Gender } & \multirow{2}{*}{ Group } & \multicolumn{6}{|c|}{ OR $(95 \% \mathrm{Cl})$} \\
\hline & & & Addictive & $\mathrm{P}$ & Dominate & $\mathrm{P}$ & Recessive & $P$ \\
\hline \multirow[t]{8}{*}{ rs1459853 } & Boys & Normal & 1 & & 1 & & 1 & \\
\hline & & Pre-HT & $0.987(0.778-1.253)$ & 0.916 & $1.156(0.861-1.552)$ & 0.335 & $0.897(0.594-1.353)$ & 0.604 \\
\hline & & $\mathrm{HT}$ & $1.089(0.861-1.378)$ & 0.476 & $1.253(0.84-1.869)$ & 0.270 & $1.013(0.681-1.506)$ & 0.949 \\
\hline & & Pre-HT + HT & $1.037(0.87-1.236)$ & 0.687 & $1.217(0.915-1.62)$ & 0.178 & $0.953(0.706-1.287)$ & 0.755 \\
\hline & Girls & Normal & 1 & & 1 & & 1 & \\
\hline & & Pre-HT & $1.146(0.911-1.441)$ & 0.244 & $1.417(0.945-2.126)$ & 0.092 & $1.049(0.714-1.541)$ & 0.807 \\
\hline & & $\mathrm{HT}$ & $1.132(0.898-1.427)$ & 0.295 & $0.997(0.68-1.462)$ & 0.989 & $1.396(0.963-2.023)$ & 0.078 \\
\hline & & Pre-HT + HT & $1.138(0.958-1.352)$ & 0.141 & $1.183(0.884-1.583)$ & 0.260 & $1.212(0.914-1.607)$ & 0.182 \\
\hline \multirow[t]{9}{*}{ rs2229202 } & Boys & Normal & 1 & & 1 & & 1 & \\
\hline & & Pre-HT & $1.219(0.931-1.596)$ & 0.150 & $1.321(0.901-1.937)$ & 0.154 & $1.437(0.8-2.58)$ & 0.225 \\
\hline & & HT & $1.142(0.869-1.501)$ & 0.340 & $1.577(1.092-2.277)$ & 0.015 & $0.52(0.225-1.204)$ & 0.127 \\
\hline & & Pre-HT + HT & $1.181(0.964-1.447)$ & 0.109 & $1.449(1.095-1.917)$ & 0.009 & $0.84(0.501-1.408)$ & 0.508 \\
\hline & Girls & Normal & 1 & & 1 & & 1 & \\
\hline & & Pre-HT & $1.118(0.855-1.463)$ & 0.415 & $1.226(0.841-1.787)$ & 0.290 & $1.044(0.553-1.969)$ & 0.895 \\
\hline & & HT & $1.204(0.925-1.568)$ & 0.167 & $1.216(0.83-1.784)$ & 0.316 & $1.535(0.877-2.687)$ & 0.134 \\
\hline & & Pre-HT + HT & $1.159(0.949-1.416)$ & 0.147 & $1.219(0.917-1.619)$ & 0.172 & $1.282(0.82-2.003)$ & 0.276 \\
\hline & Boys & Normal & 1 & & 1 & & 1 & \\
\hline \multirow[t]{7}{*}{ rs3806777 } & & Pre-HT & $1.044(0.787-1.384)$ & 0.765 & $1.033(0.716-1.492)$ & 0.861 & $1.14(0.593-2.191)$ & 0.695 \\
\hline & & $\mathrm{HT}$ & $0.976(0.734-1.297)$ & 0.865 & $1.02(0.711-1.462)$ & 0.916 & $0.788(0.371-1.674)$ & 0.535 \\
\hline & & Pre-HT + HT & $1.01(0.818-1.246)$ & 0.927 & $1.028(0.784-1.348)$ & 0.841 & $0.959(0.572-1.61)$ & 0.875 \\
\hline & Girls & Normal & 1 & & 1 & & 1 & \\
\hline & & Pre-HT & $1.127(0.869-1.46)$ & 0.367 & $1.104(0.779-1.564)$ & 0.579 & $1.371(0.783-2.401)$ & 0.269 \\
\hline & & $\mathrm{HT}$ & $0.81(0.606-1.083)$ & 0.155 & $0.847(0.589-1.22)$ & 0.373 & $0.471(0.201-1.103)$ & 0.083 \\
\hline & & Pre-HT + HT & $0.967(0.79-1.185)$ & 0.747 & $0.972(0.746-1.266)$ & 0.832 & $0.911(0.56-1.48)$ & 0.706 \\
\hline \multirow[t]{8}{*}{ rs3806782 } & Boys & Normal & 1 & & 1 & & 1 & \\
\hline & & Pre-HT & $0.792(0.433-1.448)$ & 0.449 & $0.753(0.384-1.474)$ & 0.407 & $0.938(0.12-7.324)$ & 0.951 \\
\hline & & $\mathrm{HT}$ & $0.704(0.378-1.311)$ & 0.269 & $0.726(0.377-1.399)$ & 0.338 & / & / \\
\hline & & Pre-HT + HT & $0.749(0.477-1.175)$ & 0.208 & $0.741(0.454-1.208)$ & 0.230 & $0.491(0.063-3.819)$ & 0.497 \\
\hline & Girls & Normal & 1 & & 1 & & 1 & \\
\hline & & Pre-HT & $1.233(0.726-2.095)$ & 0.438 & $1.374(0.745-2.535)$ & 0.309 & $0.722(0.092-5.673)$ & 0.757 \\
\hline & & $\mathrm{HT}$ & $1.597(1-2.551)$ & 0.050 & $1.985(1.145-3.441)$ & 0.015 & $0.673(0.085-5.308)$ & 0.707 \\
\hline & & Pre-HT + HT & $1.417(0.972-2.066)$ & 0.070 & $1.67(1.077-2.588)$ & 0.022 & $0.696(0.152-3.191)$ & 0.641 \\
\hline \multirow[t]{8}{*}{ rs7698460 } & Boys & Normal & 1 & & 1 & & 1 & \\
\hline & & Pre-HT & $0.997(0.73-1.362)$ & 0.985 & $1.023(0.709-1.476)$ & 0.905 & $0.849(0.331-2.176)$ & 0.733 \\
\hline & & HT & $0.962(0.704-1.314)$ & 0.806 & $0.975(0.678-1.403)$ & 0.893 & $0.833(0.322-2.156)$ & 0.706 \\
\hline & & Pre-HT + HT & $0.978(0.776-1.234)$ & 0.853 & $0.997(0.76-1.309)$ & 0.985 & $0.84(0.417-1.694)$ & 0.627 \\
\hline & Girls & Normal & 1 & & 1 & & 1 & \\
\hline & & Pre-HT & $0.97(0.706-1.332)$ & 0.849 & $1.009(0.704-1.447)$ & 0.960 & $0.642(0.196-2.102)$ & 0.464 \\
\hline & & $\mathrm{HT}$ & $1.267(0.936-1.714)$ & 0.126 & $1.279(0.895-1.828)$ & 0.176 & $1.583(0.69-3.63)$ & 0.278 \\
\hline & & Pre-HT + HT & $1.111(0.882-1.399)$ & 0.373 & $1.135(0.869-1.484)$ & 0.352 & $1.096(0.539-2.227)$ & 0.800 \\
\hline \multirow[t]{8}{*}{ rs3796576 } & Boys & Normal & 1 & & 1 & & 1 & \\
\hline & & Pre-HT & $0.918(0.663-1.271)$ & 0.607 & $0.887(0.608-1.292)$ & 0.531 & $1.033(0.405-2.634)$ & 0.946 \\
\hline & & HT & $1.109(0.817-1.505)$ & 0.508 & $1.09(0.758-1.567)$ & 0.643 & $1.377(0.609-3.114)$ & 0.443 \\
\hline & & Pre-HT + HT & $1.013(0.803-1.279)$ & 0.912 & $0.986(0.75-1.296)$ & 0.918 & $1.208(0.635-2.299)$ & 0.565 \\
\hline & Girls & Normal & 1 & & 1 & & 1 & \\
\hline & & Pre-HT & $1.224(0.926-1.618)$ & 0.155 & $1.247(0.882-1.763)$ & 0.211 & $1.455(0.725-2.922)$ & 0.292 \\
\hline & & $\mathrm{HT}$ & $1.001(0.743-1.348)$ & 0.996 & $0.971(0.677-1.392)$ & 0.872 & $1.159(0.536-2.506)$ & 0.708 \\
\hline & & Pre-HT + HT & $1.112(0.897-1.38)$ & 0.333 & $1.105(0.849-1.439)$ & 0.456 & $1.306(0.751-2.271)$ & 0.344 \\
\hline
\end{tabular}

Adjusted for age, gender, TC, TG, HDL-C, LDL-C, BMI. The OR values were compared with the normal group. SNPs, single nucleotide polymorphisms; M, major allele; $\mathrm{m}$, minor allele; OR, odds ratio; Cl, confidence interval; HT, hypertension; TC, total cholesterol; TG, triglycerides; HDL-C, high-density lipoprotein cholesterol; LDL-C, low-density lipoprotein cholesterol; BMI, body mass index. 